\title{
Effect of Sigma Phase on Fracture Behavior of Steels and Weld Joints of Components in Power Industry Working at Supercritical Conditions
}

\author{
Zdeněk Kuboň, Šárka Stejskalová and \\ Ladislav Kander \\ Additional information is available at the end of the chapter \\ http://dx.doi.org/10.5772/intechopen.71569
}

\begin{abstract}
This chapter deals with the change of the structure and mechanical properties of the austenitic steels grades TP347HFG, Super 304H and HR3C as well as their welded joints after the exposure at temperatures corresponding to the ultra-super critical (USC) and advanced ultra-super critical (A-USC) parameters. Several tube bend radii were investigated in order to understand relation between cold work plastic deformation, mechanical properties and the structural changes with special attention to the generation of sigma phase during long-term high temperature exposure. The effect of post bend solution annealing work on the material properties and structural changes was studied, too, using small punch test (SPT) and miniaturized tensile tests taken both from straight part and extrados of bends under investigation. Creep properties of either base metal either welded joints were tested and evaluated using standard creep specimens at temperatures 650,700 and $750^{\circ} \mathrm{C}$. The obtained results confirmed that the mechanical properties and the structure were significantly influenced even after relatively short-time exposure at elevated temperature. The results of experiments were compared with other results obtained from analyses of tubes after $100,000 \mathrm{~h}$ of exposure in a USC block where extensive precipitation of sigma phase was also identified.
\end{abstract}

Keywords: $\sigma$-phase, austenitic steels, tube bends, weld joints, creep properties

\section{Introduction}

The utilization of ultra-super critical (USC) boilers working with advanced steam parameters (typically $600 / 620^{\circ} \mathrm{C}$ and $28.5 \mathrm{MPa}$ ) has led to the development of new materials with improved 
long-term creep properties. In order to meet the demanding conditions, new grades of lowalloy steels for waterwalls, modified chromium steels for headers and pipelines as well as austenitic steels and nickel superalloys for the final stages of superheaters and reheaters (RHs) have been developed. The investigation of the functional properties and further development of groups of materials is thus the key factor in the design and construction of new power units.

The effort to improve creep resistance of austenitic steels based on $18 \mathrm{Cr}-8 \mathrm{Ni}$ series, originally developed as corrosion resistant materials, was initiated in 1970s. Similarly, the improvement of creep resistance of $25 \mathrm{Cr}-20 \mathrm{Ni}$ series for demanding corrosive conditions has started in 1980s. Figure 1 shows the development of austenitic creep-resistant steels for fossil fired power plant applications [1].

Austenitic heat-resistant steels for boiler applications of $18 \mathrm{Cr}-8 \mathrm{Ni}$ series are used in the understabilized condition, the content of strong carbide forming elements $(\mathrm{Ti}, \mathrm{Nb})$ is decreased and $\mathrm{M}_{23} \mathrm{C}_{6}$ carbide contributes to the precipitation strengthening of the steel. Thanks to the working conditions at high temperatures, austenitic creep-resistant steels do not need to be resistant to the intergranular corrosion caused by precipitation of $\mathrm{M}_{23} \mathrm{C}_{6}$ carbides on grain boundaries and high temperature also enable fast healing effect due to fast diffusion of chromium to the chromium depleted zone around carbide on the grain boundary.

Figure 2 shows the increase of creep rupture strength of heat-resistant boiler steels at $600^{\circ} \mathrm{C}$ after 100,000 h for materials developed during the twentieth century [2].

\section{Advanced austenitic steels for USC boilers and their material characteristics}

The austenitic steels of AISI 304(H) and AISI 316(H) type used in boilers, where the temperature of the superheater tubes can exceed $650^{\circ} \mathrm{C}$, suffer from significant steam-side oxide

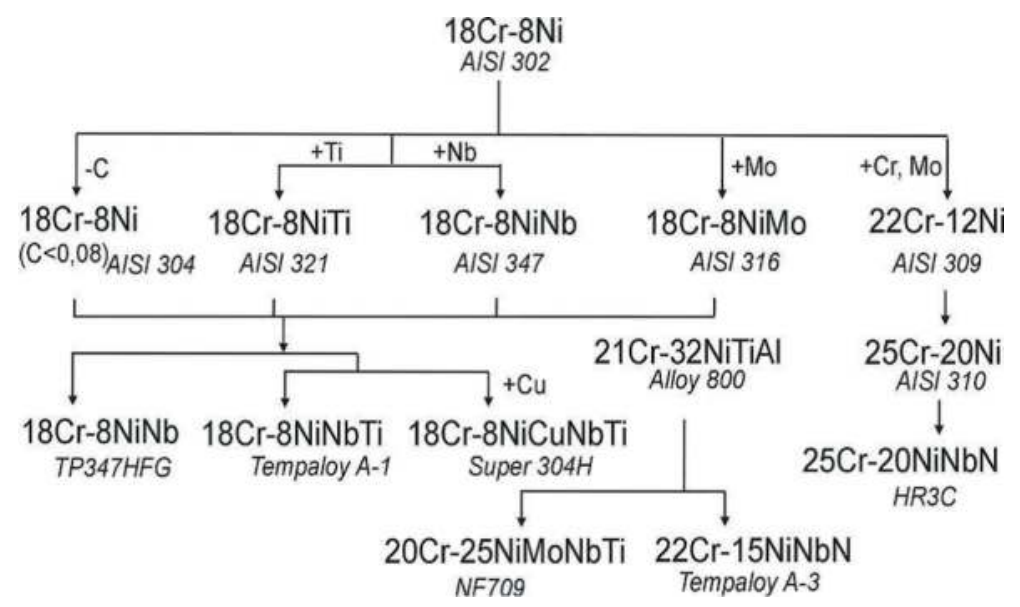

Figure 1. Development of austenitic creep-resistant steels for power plants [1]. 


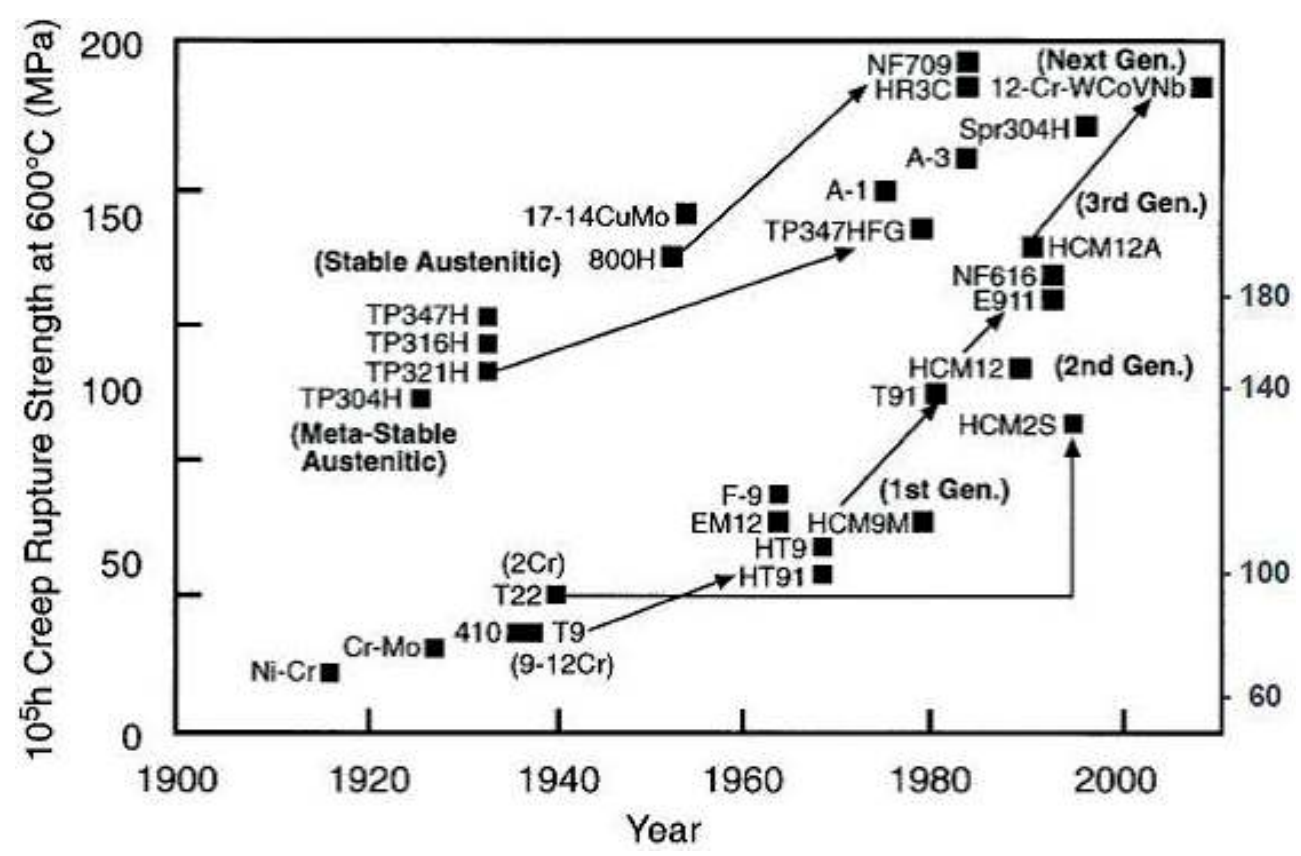

Figure 2. Increase of $100,000 \mathrm{~h}$ creep rupture strength of types and grades of creep-resistant steels at $600^{\circ} \mathrm{C}$ [2].

spallation resulting in overheating and subsequent creep fracture of the tubes [3]. This spallation occurs due to different thermal expansion of the steel and the oxides on the steamside surface of the tube. The compactness of the oxide layer in austenitic steels then causes spallation of the almost entire protective oxide layer during sudden temperature changes.

Efforts to increase the steam oxidation resistance as well as creep strength at temperatures above $650^{\circ} \mathrm{C}$ resulted in the development and successful use of advanced austenitic heatresistant steels for USC boilers known as Super 304H (1.4907, X10CrNiCuNb 18-9-3), HR3C (1.4952, X6CrNiNbN 25-20) and TP347HFG (1.4908, X8CrNi 19-11). The chemical composition and mechanical properties are shown in Tables 1 and 2, respectively.

Chemical composition of steel Super $304 \mathrm{H}$ has been changed in comparison to the grade AISI $304 \mathrm{H}$ by the addition of $3 \% \mathrm{Cu}$ and alloying by niobium and nitrogen. Copper forms particles of $\varepsilon$-phase in the matrix, that is, small spherical precipitates that significantly strengthen the matrix. Minimal changes were made to TP347HFG compared to the former grade TP347H, the niobium to carbon ratio was increased and special heat treatment that guaranties a fine-grained structure was developed. Steel HR3C has balanced nitrogen and niobium contents, which should increase creep resistance and reduce the susceptibility to the formation of undesirable hard and brittle $\sigma$-phase [4]. The change of chemical composition, namely addition of niobium increased precipitation strengthening of these steel grades and copper in Super $304 \mathrm{H}$ steel further increased its creep rupture strength. All of them (TP347H, Super 304H and HR3C) have been successfully used as superheater/reheater tubes in USC power plants all over the world. 


\begin{tabular}{lllllllllllll}
\hline Grade & $\mathbf{C}$ & $\mathbf{S i}$ & $\mathbf{M n}$ & $\mathbf{P}$ & $\mathbf{S}$ & $\mathbf{C r}$ & $\mathbf{N i}$ & $\mathbf{B}$ & $\mathbf{C u}$ & $\mathbf{N b}$ & $\mathbf{A l}$ & $\mathbf{N}$ \\
\hline Super 304H & 0.07 & max. & $\max$. & $\max$. & $\max$. & 17.0 & 7.5 & 0.001 & 2.50 & 0.30 & 0.003 & 0.05 \\
& 0.13 & 0.30 & 1.00 & 0.040 & 0.010 & 19.0 & 10.5 & 0.010 & 3.50 & 0.60 & 0.030 & 0.12 \\
& & & & & & & & & & & & \\
HR3C & max. & max. & max. & max. & $\max$. & $23.0-$ & 17.0 & - & - & 0.20 & - & 0.15 \\
& 0.10 & 1.50 & 2.00 & 0.030 & 0.030 & 27.0 & 23.0 & & & 0.60 & & 0.35 \\
TP347HFG & $0.06-$ & max. & & & & & & & & & & \\
& 0.10 & 0.75 & 2.00 & 0.040 & 0.030 & 20.0 & 13.0 & & & & - & - \\
\hline
\end{tabular}

Table 1. Chemical composition of advanced austenitic steels (wt.\%).

\begin{tabular}{|c|c|c|c|c|c|c|}
\hline \multirow[t]{2}{*}{ Grade } & $\mathbf{R}_{\mathrm{p} 0.2}$ & $\mathbf{R}_{\mathrm{m}}$ & $\mathrm{R}_{\mathrm{p} 0.2}\left(650^{\circ} \mathrm{C}\right)$ & $\mathbf{A}$ & $\mathrm{KV}\left(+20^{\circ} \mathrm{C}\right)$ & $\mathrm{R}_{\mathrm{uT}} / 650^{\circ} \mathrm{C} / 10^{5} \mathrm{~h}$ \\
\hline & (MPa) & (MPa) & (MPa) & $(\%)$ & (J) & (MPa) \\
\hline Super $304 \mathrm{H}$ & $\geq 235$ & $590-850$ & 135 & $\geq 35$ & 85 & 116 \\
\hline HR3C & $\geq 295$ & $655-900$ & 180 & $\geq 30$ & 85 & 114 \\
\hline TP347HFG & $\geq 205$ & $550-750$ & 126 & $\geq 35$ & 85 & 100 \\
\hline
\end{tabular}

Table 2. Mechanical properties of advanced austenitic steel grades.

\section{Precipitation of sigma phase}

The $\sigma$-phase is an intermetallic phase that forms in more than 50 transition alloys. The technically most important is $\sigma$-phase precipitation in $\mathrm{Fe}-\mathrm{Cr}$ system. The $\sigma$-phase has a tetragonal crystal lattice and precipitates between 600 and $1000^{\circ} \mathrm{C}$ [5-7]. The chromium contents in the $\sigma$-phase containing alloys is usually in range from 25 to $76 \mathrm{wt} . \%$. In alloys with lower chromium content can sigma phase contain other alloying elements as well. In the $\mathrm{Cr}-\mathrm{Ni}$ austenitic steels, sigma phase formation is encouraged by increasing $\mathrm{Cr}$ content above 17-20 wt.\%, and is discouraged by an increase in Ni content. Since the sigma phase is $\mathrm{Cr}$-rich phase, the diffusion of $\mathrm{Cr}$ is usually regarded as one of the controlling factors for its precipitation. Besides chromium and carbon contents, many other factors affect the formation of $\sigma$-phase. Diffusion of another substitutional element like Mo could also be important [8]. In general, all ferriteforming elements like $\mathrm{Cr}, \mathrm{Nb}, \mathrm{Ti}, \mathrm{Mo}$ or $\mathrm{W}$ promote precipitation of $\sigma$-phase. Silicon also promotes and accelerates $\sigma$-phase formation. Due to differences in diffusion rate of alloying elements, the formation of $\sigma$-phase in austenite is about 100 times slower than in ferrite. Consequently, the presence of $\delta$-ferrite in austenitic alloys accelerates $\sigma$-phase precipitation [9]. The $\delta$-ferrite (BCC), compared to the $\gamma$-austenite (FCC), is a chromium-rich region where the diffusion of chromium and other ferrite-forming elements is faster. Hence, $\delta$-ferrite is naturally a beneficial site for the precipitation of the $\sigma$-phase [10]. Therefore, in steels containing 
some ferrite or in which ferrite forms temporarily during aging, will $\sigma$-phase be formed via the ferrite.

The $\sigma$ phase forming tendency of an alloy can be predicted according to the electron vacancy number originally developed by Woodyatt et al. [11] in the form

$$
N_{V}=0.66 \mathrm{Ni}+1.71 \mathrm{Co}+2.66 \mathrm{Fe}+4.66(\mathrm{Cr}+\mathrm{Mo}+\mathrm{W})+5.66 \mathrm{~V}+6.66 \mathrm{Zr}+10.66 \mathrm{Nb}[\mathrm{at} .]
$$

When the calculated value of electron vacancy number is greater than 2.52 , $\sigma$-phase should form.

Since the $\sigma$-phase presence is closely related to the $\mathrm{M}_{23} \mathrm{C}_{6}$, there is a preposition that $\mathrm{M}_{23} \mathrm{C}_{6}$ acts as the precursor to the $\sigma$-phase [12-14]. Pre-existence of carbides in the steel can be an intensifying factor for $\sigma$-phase formation, as the formed carbides have high chromium content and can act as the source of chromium. The formation from $\mathrm{M}_{7} \mathrm{C}_{3}$ carbides is faster than from $\mathrm{M}_{23} \mathrm{C}_{6}$, probably due to instability of $\mathrm{M}_{7} \mathrm{C}_{3}$ carbide [15].

Other authors [16] stated that in situ transformation of $\mathrm{M}_{23} \mathrm{C}_{6}$ to the $\sigma$-phase is improbable, although they tend to be in contact. A study on the precipitation sequence in $316 \mathrm{~L}$ steel at temperatures up to $500^{\circ} \mathrm{C}$ has found that the formation of the $\sigma$-phase precedes that of $\mathrm{M}_{23} \mathrm{C}_{6}$. This work has pointed out that the precursors to the $\sigma$-phase in this temperature range are in fact precipitates forming on dislocations and grain boundaries, which are not possible to identify even by using high resolution TEM (HR-TEM) because of their extremely small sizes [17].

In stainless steels, classification of the morphology of the $\sigma$-phase can be divided into four types [4]:

1. Grain boundary precipitation,

2. Triple point precipitation,

3. Corner precipitation and

4. Cellular precipitation.

\section{1. $\delta$-Ferrite/austenite grain boundary precipitation}

The $\sigma$-phase easily precipitates at the $\delta / \gamma$ phase boundary, which is a region with high concentration of chromium. At the same time, it is a high interface energy site and a beneficial site for the heterogeneous nucleation thank to high concentration of lattice defects. When the $\sigma$-phase nucleates at the $\delta / \gamma$ interphase boundary, some defects disappear, which releases the free energy of the system. Consequently, the activation energy barrier to form a coherent interface is reduced. This case is typical for austenitic stainless steels. 


\subsection{Triple point precipitation}

The $\sigma$-phase precipitates also at the triple point of the $\delta$-ferrite boundary. According to Barcik [9], $\sigma$-phase precipitates first on triple points and then on grain faces. After long-term aging at high temperature, it also forms on the coherent twin boundaries and intragranular inclusions.

\subsection{Corner precipitation}

The corner precipitation of the $\sigma$-phase means that it precipitates directly at the corner $\delta$-ferrite particles because the $\delta$-ferrite has a high $\mathrm{Cr}$ content phase, and $\sigma$-phase prefers to nucleate and precipitate at that point. When the $\sigma$-phase precipitates at the corner $\delta$-ferrite, it consumes the $\mathrm{Cr}$ from the $\delta$-ferrite particles.

\subsection{Cellular precipitation}

Cellular precipitation means that the $\sigma$-phase and secondary austenite $\left(\sigma+\gamma_{2}\right)$ precipitate as laminar precipitation in the $\delta$-ferrite particles. This reaction is called the eutectoid decomposition of $\delta \rightarrow \sigma+\gamma_{2}$. When the eutectoid decomposition of $\delta \rightarrow \sigma+\gamma_{2}$ is finished, the $\sigma$-phase consumes the $\mathrm{Cr}$, Mo and $\mathrm{Si}$ from the $\delta$-ferrite particles.

The direct precipitation of $\sigma$-phase in austenite is in general very slow and takes thousands of hours due to:

- very low carbon and nitrogen solubility in $\sigma$-phase, which means that the both elements have to form carbide and nitride before $\sigma$-phase precipitation,

- very slow diffusion rate of substitutional elements in austenite and

- incoherent boundary between $\sigma$-phase and austenite, which makes $\sigma$-phase nucleation difficult.

Figure 3 shows the precipitation mechanism of $\sigma$-phase in AISI 316 L stainless steel at different aging temperatures. Without heating $\left(\mathrm{t}_{0}\right)$, the $\delta$-ferrite precipitates at the $\delta / \gamma$ interphase boundary and $\gamma$-phase. When the aging temperature increases to $t_{1}$, the $\sigma$ and $\gamma_{2}$-phases precipitate in $\delta$-ferrite particles. When the aging temperatures increases to $t_{2}$, the cellular $\sigma+\gamma_{2}$ also forms in $\delta$-ferrite particles, and the $\sigma$-phase precipitates at the triple points and the $\delta / \gamma$ interphase boundaries. When the aging temperature is $t_{3^{\prime}}$ the precipitation of the laminar $\sigma+\gamma_{2}$ is more pronounced than at the other aging temperatures [18].

When the $\delta$-ferrite to $\sigma$-phase transformation occurs, the $\sigma$-phase precipitates in the $\mathrm{Cr}$-enriched region of $\delta$-ferrite, directly in $\delta$-ferrite particles. The precipitation of $\sigma$-phase is a diffusion-controlled phase transformation in $25 \% \mathrm{Cr}-20 \% \mathrm{Ni}$ stainless steel, where $\mathrm{Cr}$ atoms have an important effect on acceleration of the precipitation rate of $\sigma$-phase [19]. The precipitation rate of $\sigma$-phase in $\delta$-ferrite is therefore about 100 times higher than in $\gamma$-austenite $[9,20]$. After $\sigma$-phase precipitation, will the content of $\mathrm{Cr}$ and $\mathrm{Mo}$ in $\delta$-ferrite decrease and simultaneously will $\mathrm{Ni}$ content increase. This fact leads to the formation of secondary austenite phases $\left(\gamma_{2}\right)$ through the $\delta$-ferrite [21]. The plate $\sigma$-phase and $\gamma_{2}$-precipitate in $\delta$-ferrite particles were observed in microstructures of AISI 304 stainless steel aged at 595 and $650^{\circ} \mathrm{C}$ for $31,000 \mathrm{~h}$ [22]. The precipitation 
mechanism is through the eutectoid decomposition of $\delta$-ferrite into $\sigma$-phase and $\gamma_{2}$-austenite and is similar at both temperatures, but at $650^{\circ} \mathrm{C}$ it was more evident (see Figures 4 and 5).

In stabilized grades, the formation of $\sigma$-phase is faster than in other grades. Minami et al. reported precipitation of $\sigma$-phase in most of the grades of austenitic stainless steels: type AISI 304, 316, 321 and 347, but it forms after different times (in 347 and 321 already after $1000 \mathrm{~h}$ at $700^{\circ} \mathrm{C}$ but in 304,316 and Tempaloy-A1, $\sigma$-phase was found in significant quantities only after 10,000 h, see Figure 5 (the percentage of $\sigma$-phase equals to the area etched by $\mathrm{KOH}$ ) [23].

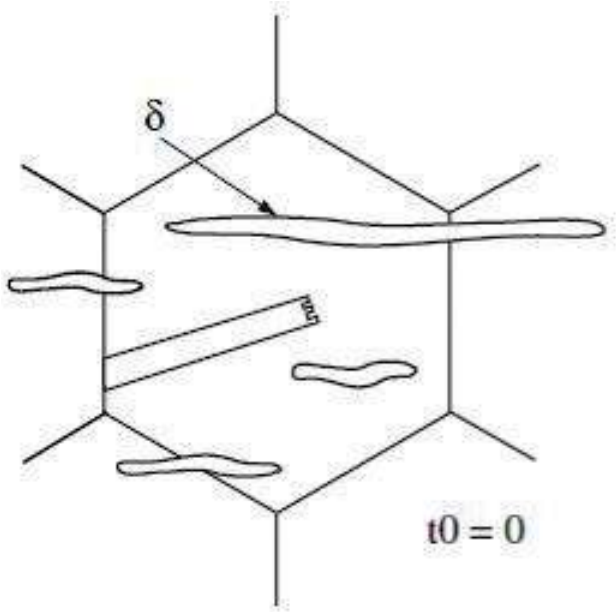

(a)

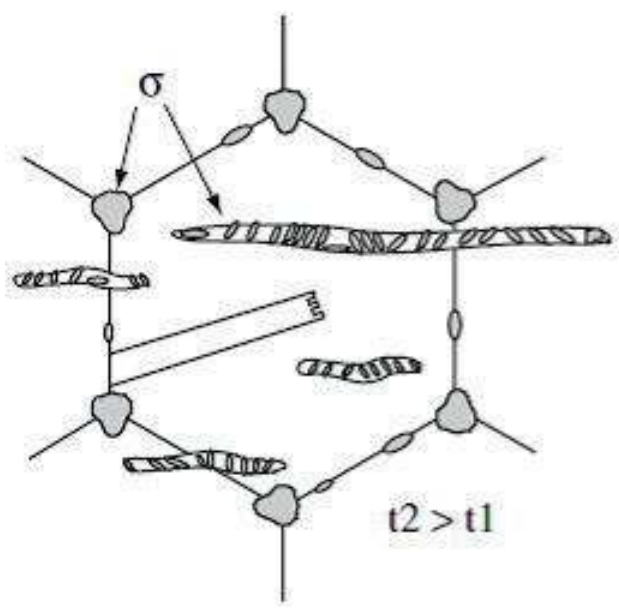

(c)

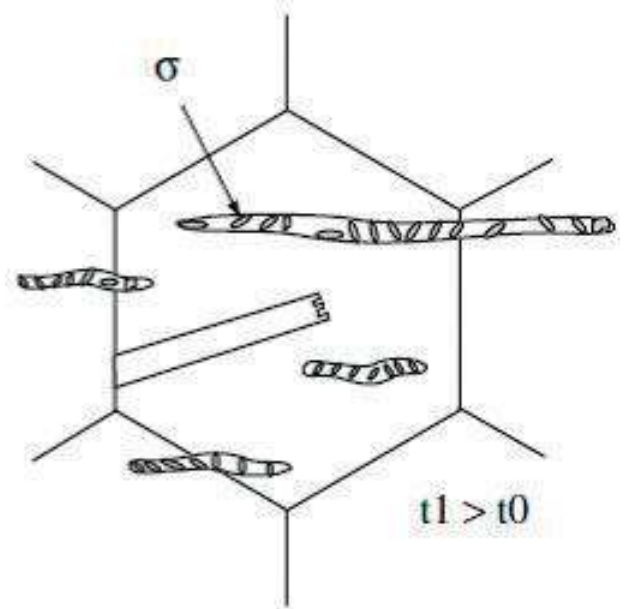

(b)

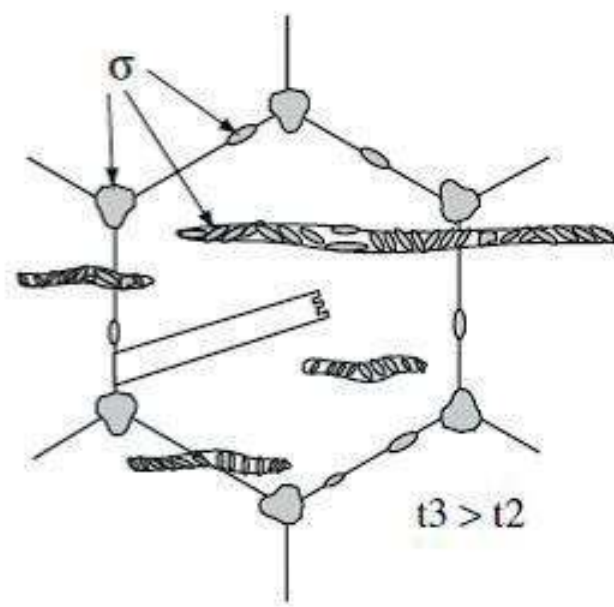

(d)

Figure 3. Precipitation mechanisms of $\sigma$-phase in AISI 316 L stainless steel [18]. 


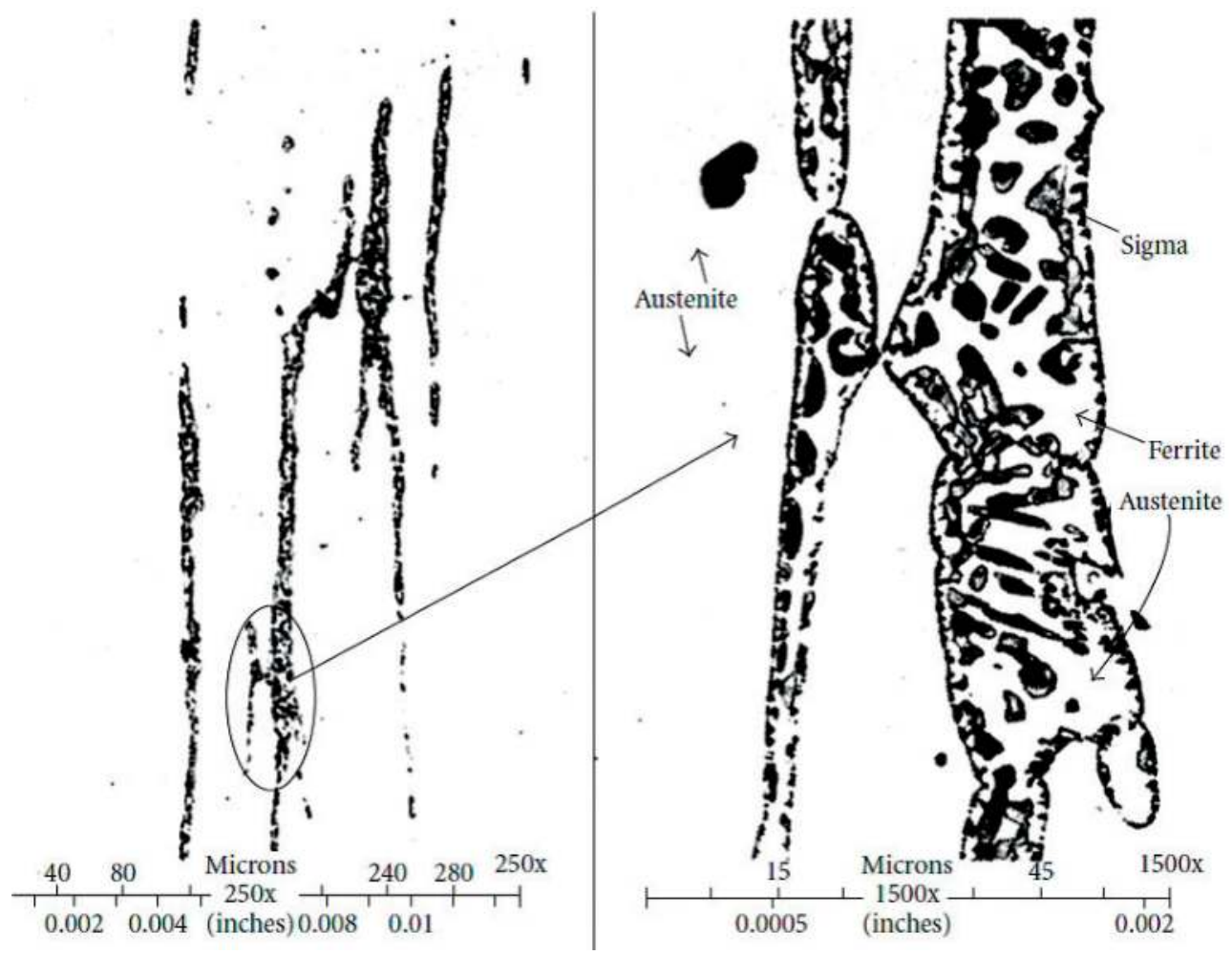

Figure 4. Microstructural observation of the $\delta \rightarrow \sigma+\gamma_{2}$ phase transformation in AISI 304 stainless steel $\left(595^{\circ} \mathrm{C}, 31,000 \mathrm{~h}\right)[15]$.

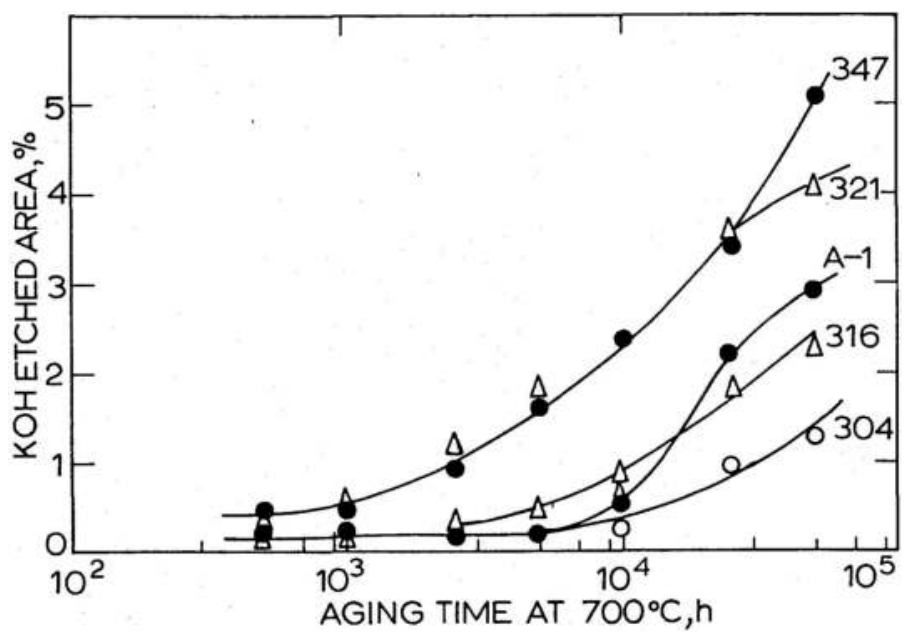

Figure 5. Precipitation of $\sigma$-phase in different grades of austenitic stainless steels [23]. 
According to Ref. [23], the behavior of Tempaloy-A1, which is 18/10 steel stabilized with Nb, but its $\mathrm{Nb} / \mathrm{C}$ ratio is only 1.86 compared to 17.40 in the steel 347 , supports the observation that $\sigma$-phase forms in steels with chromium equivalent higher than $18 \mathrm{wt} . \%$ when the carbon content falls below a critical value. In the 347 , almost all the carbon is rapidly precipitated as $\mathrm{NbC}$, while the low $\mathrm{Nb}$ content of Tempaloy-A1 means that a part of carbon is still dissolved in the solid solution. The different trend for 321 could be linked to the instability of TiC with regard to $\mathrm{M}_{23} \mathrm{C}_{6}$. The precipitation of $\mathrm{M}_{23} \mathrm{C}_{6}$ lowers both the carbon and the chromium contents.

The formation of $\sigma$-phase in austenitic stainless steel greatly depends on grain size, as it affects the density of nucleation sites [9]. According to Ref. [24] in austenitic stainless steels, both the grain size and grain shape influence sigma precipitation because grain boundaries represent high-energy nucleation sites for nucleation of $\sigma$-phase [25]. Fine-grained structure then provides more $\sigma$-phase formation.

The same is true for cold deformation, however, the effect of cold work on $\sigma$-phase precipitation depends mainly on its influence on recrystallization. The $\sigma$-phase formation is enhanced if the amount of deformation energy is sufficient to generate recrystallization at operating temperature. If the amount of cold work is too low and recrystallization does not occur, $\sigma$-phase formation can be actually retarded [26]. Hot working enhances $\sigma$-phase precipitation, as it was demonstrated on a duplex stainless steel hot deformed at $900^{\circ} \mathrm{C}$. Hot deformation induces lattice defects which act as favorable sites for $\sigma$-phase precipitation. Higher total content of $\sigma$-phase in the specimen deformed at the lower strain rate $\left(0.01 \mathrm{~s}^{-1}\right)$ compared to the sample deformed at $1 \mathrm{~s}^{-1}$ was explained by the difference in density and velocity of dislocations. Deformation at high strain rates results in higher dislocation density, which means precipitation of fine $\sigma$-phase particles throughout the whole specimen. These fine particles grow slowly, because they are in contact with individual dislocations for shorter time. As a result, material deformed at high strain rates has plenty of fine $\sigma$-phase particles but the total volume fraction of $\sigma$-phase is greater in samples deformed at lower strain rates [27].

\section{Presence of sigma phase in the tube bends after high temperature exposure}

Extensive experimental work confirmed the effect of cold bending on $\sigma$-phase precipitation. The study includes advanced steels for USC boilers. The effect of technology and high temperature exposure was evaluated (see Figure 6).

Series of tube bends were analyzed. The first part were cold worked bends without any further heat treatment (referred to as-bended state), the second part were heat-treated tubes after bending (referred to post-bend heat treatment-PBHT), third part of test program focused on evaluation of structural changes and changes in mechanical properties after exposure at high temperature.

The mechanical properties and fracture behavior were examined using miniaturized tensile tests and small punch test (SPT). The effect of plastic deformation applied during the bending 
of tubes on the microstructure and the mechanical properties were also studied. The positive effect of solution annealing on the microstructure was quantified as well [28, 29].

During the third part of the experimental program the tube bends exposed to high temperature in the boiler without any loading were investigated. The effect of high temperature exposure on formation of $\sigma$-phase and fracture energy after exposure was evaluated.

Bend tubes $\varnothing 38 \times 6.3$ of Grades TP347HFG, Super 304H and HR3C and the bend radii R60, R80 and R100 were tested (see Tables 1 and 2). The samples of the tube bends were cut out from bended part of tubes (see Figure 7). The samples were then evaluated in as-received conditions (with PBHT and without PBHT) and installed into a boiler without any loading for 1 year at temperature ranges from 635 to $695^{\circ} \mathrm{C}$ and 726 to $775^{\circ} \mathrm{C}$, respectively.

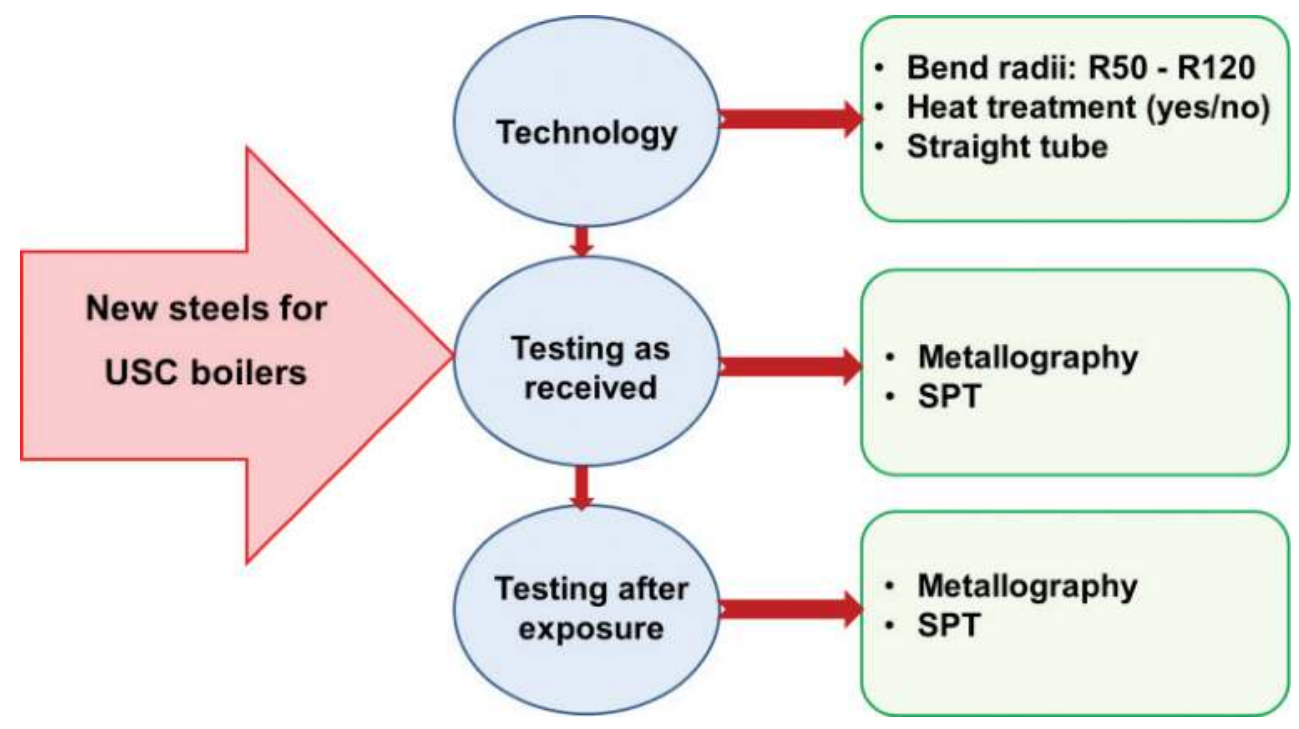

Figure 6. Diagram of evaluation of tube bends.
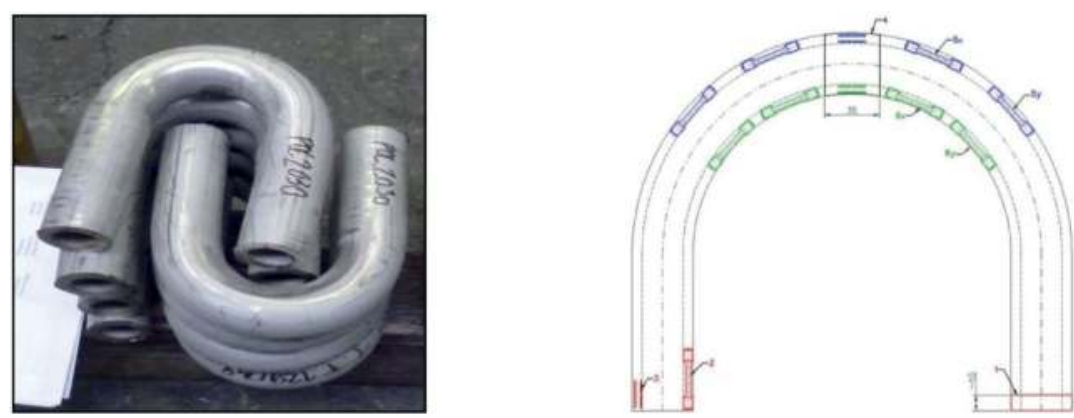

Figure 7. Samples in as-bended state under study and cutting plan. 


\section{Testing method used to evaluate mechanical properties of tube bends}

In order to understand the effect of $\sigma$-phase on material properties and microstructure, various testing methods based on miniaturized test techniques have been used. As the standard tensile test is not sensitive enough to quantify the effect of $\sigma$-phase, a special testing method, small punch test (SPT), originally developed for residual lifetime assessment of power plants components, has been used. This testing method is covered at this time by draft of ISO standard. A basic tenet of small punch test method is to penetrate small volume of experimental material (Figure 8a). The small punch testing technique utilizes a small disc specimen, $8 \mathrm{~mm}$ in diameter and $0.5 \mathrm{~mm}$ in thickness, clamped around its circumference and indented by a spherical punch up to failure [30]. Monotonic load versus displacement records are used to correlate the tensile and fracture toughness parameters (see Figure 8b). Moreover, the fracture energy can be calculated as the area under the deflection curve. All tests presented in this work were performed at room temperature.

a)

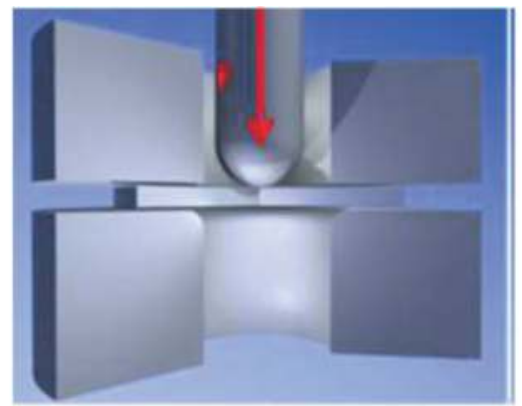

b)

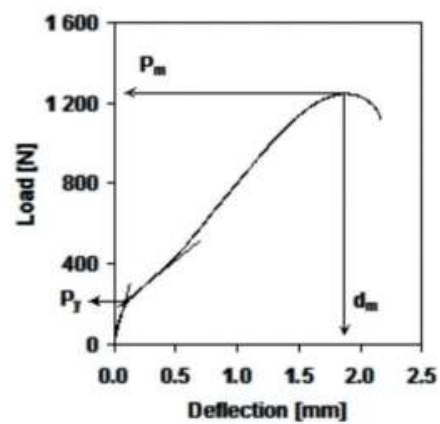

Figure 8. Principle of small punch test (a) and typical SPT record (b).

\section{Results of metallographic analyses of tube bends after exposure at high temperature}

Comparison of the structure of specimen in the as-bended state after exposure at lower and higher temperatures in the boiler for all three type steels can be seen in Figures 9-11.

Microstructural investigation showed that all tube bends that were exposed at the elevated temperature in the boiler without any loading, contain various amount of $\sigma$-phase. Amount of $\sigma$-phase depends on temperature of exposure, bend radii and heat treatment after bending. Therefore, the maximum amount was found in bends with smaller radii and without PBHT. The tube bends with smaller bending radii without PBHT, corresponds to maximum amount of cold work deformation, contain the largest amount of $\sigma$-phase for all grades. As amount of cold work deformation decrease, lower percentage of $\sigma$-phase can be observed, for example, in the structure of bend with higher radii where minimum amount of $\sigma$-phase was measured in the tube bends with bending radius R100 (Figures 9-11). 


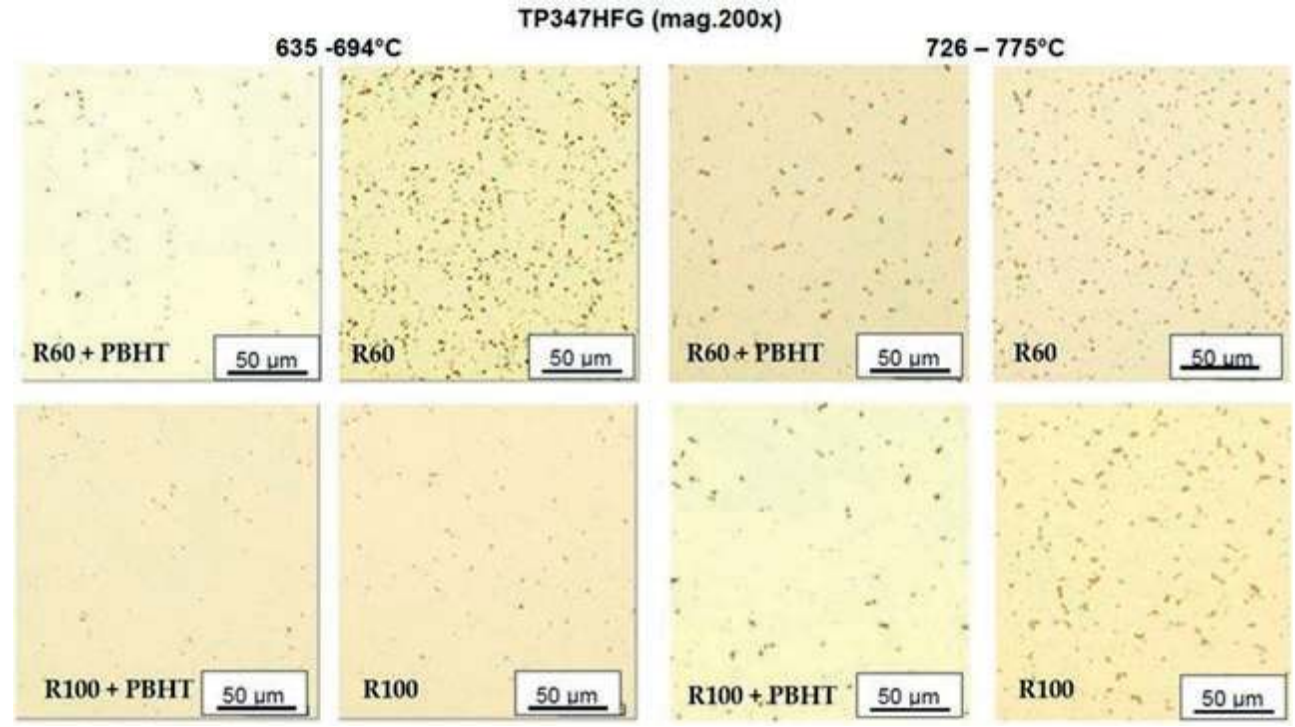

Figure 9. Comparison of the structure of specimen TP347HFG in the as-bended state after exposure at lower and higher temperatures in the boiler.

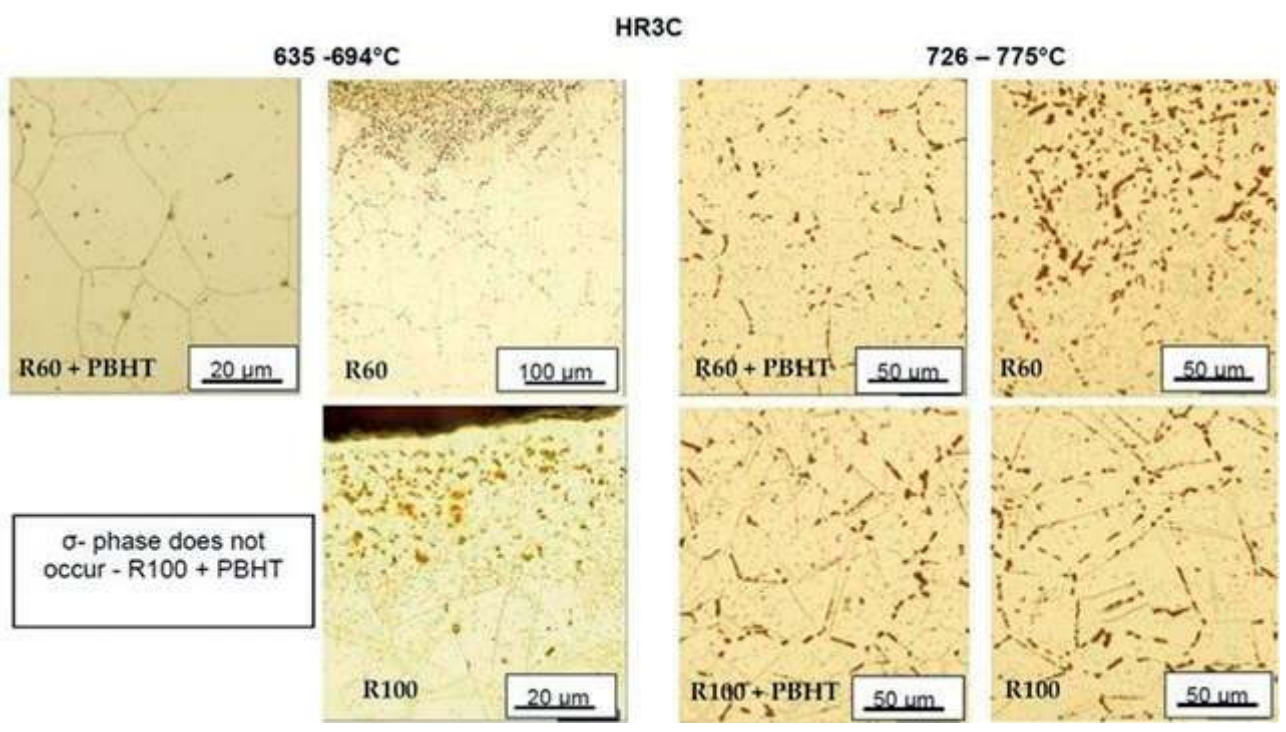

Figure 10. Comparison of the structure of specimen HR3C in the as-bended state after exposure at lower and higher temperatures in the boiler. 


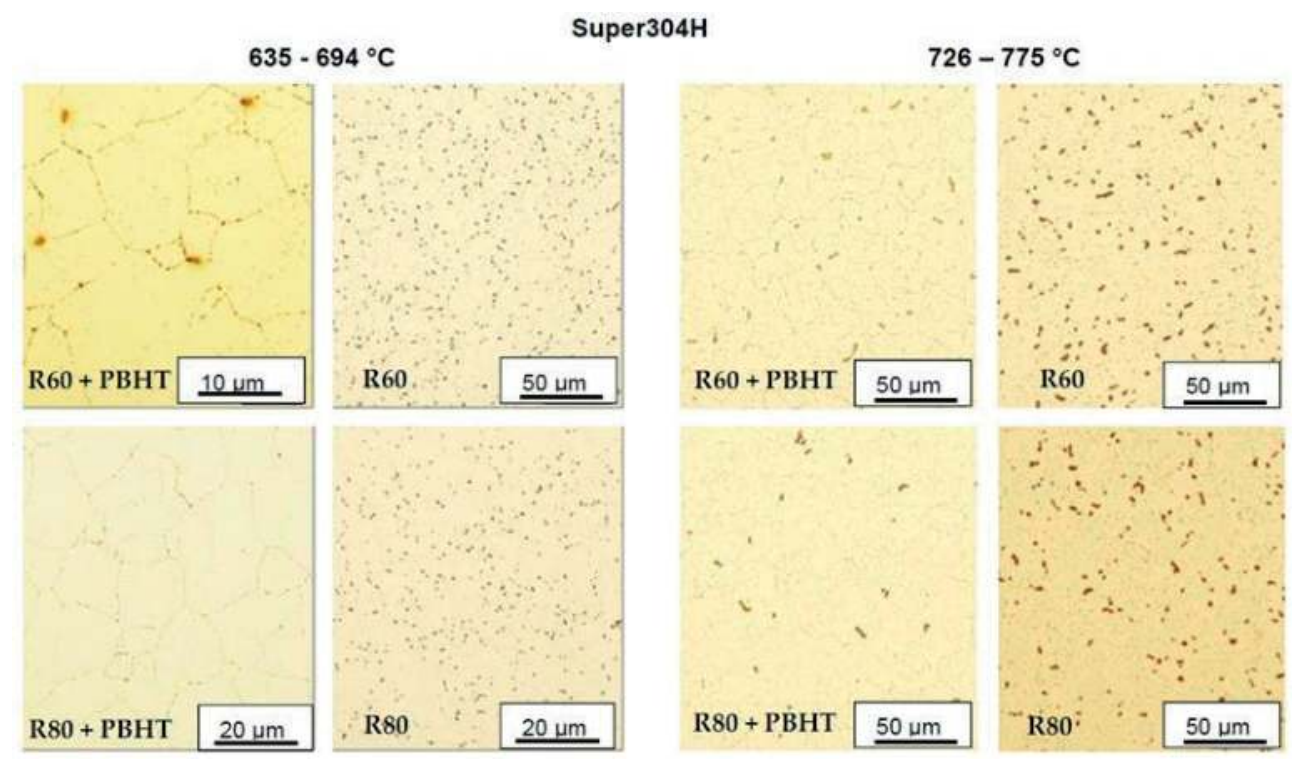

Figure 11. Comparison of the structure of specimen Super $304 \mathrm{H}$ in the as-bended state after exposure at lower and higher temperatures in the boiler.

Logically, tube bends exposed at higher temperature contain significantly higher amount of $\sigma$-phase, this fact is in very good agreement with theoretical results. The particles of $\sigma$-phase differ in quantity and in size and even in the distribution in the wall of the bent tube. Tube bends exposed at the lower temperature contain $\sigma$-phase mostly near the outer surface of extrados, corresponding to the position of the highest cold work deformation. While specimens exposed at higher temperature contain $\sigma$-phase in the whole wall of extrados.

Reciprocally, Figure 10 shows the structure of HR3C tube bend after the exposure in two locations in the boiler. The tube bend with post-bend heat treatment (PBHT) exposed at lower temperature showed very few particles of $\sigma$-phase [31].

Tube bends without PBHT contain considerably more $\sigma$-phase. Higher temperature of exposure caused the coarsening of $\sigma$-phase in the tube bends that will significantly affect toughness of materials.

\section{Effect of sigma phase on fracture energy}

As demonstrated in Figure 12, the presence of even very small volume of $\sigma$-phase in the structure means drop in fracture energy and can be clearly detected from force-displacement record of the small punch test. The test results in as-bended state and after the exposure (at lower temperature) and the test results for samples with and without PBHT were compared. Figure 12 

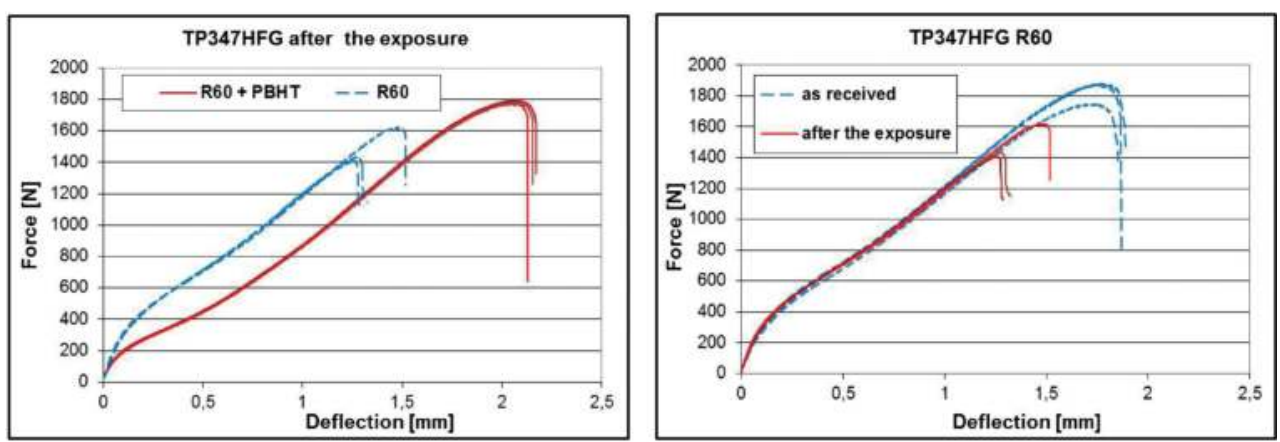

Figure 12. Force versus displacement of tube bend TP347HFG in as-bended state and after the exposure.

shows the effect of $\sigma$-phase on fracture energy represented by SPT method in TP347HFG samples and effect of PBHT for the same steel. It is clearly seen positive effect of PBHT on fracture energy as well as effect of exposure, where the fracture energy is decreased significantly.

Figure 13 shows effect of exposure on the fracture energy of HR3C steel for as-bended and PBHT state, respectively. In both examples was fracture energy significantly reduced by the high temperature exposure. In the case of as-bended tubes, changes in the slope of SPT records were identified as well. These changes can probably be connected with submicrostructural changes during exposure in this type of steel and will be studied in the future work.

Only moderate changes were identified in the case of Super 304H grade steel, see Figure 14. Drop in fracture energy is very small and no changes in the slope were recognized.

The obtained results indicate that $\sigma$-phase is one of important factors that should be remembered during high temperature exposure of these materials in USC blocks. The presence of $\sigma$-phase only at the outer surface of extrados at lower exposure temperatures and in the whole wall section of extrados at higher exposure temperature indicates, that the amount of $\sigma$-phase in the tube bends is also connected to the deformation energy introduced into the wall of
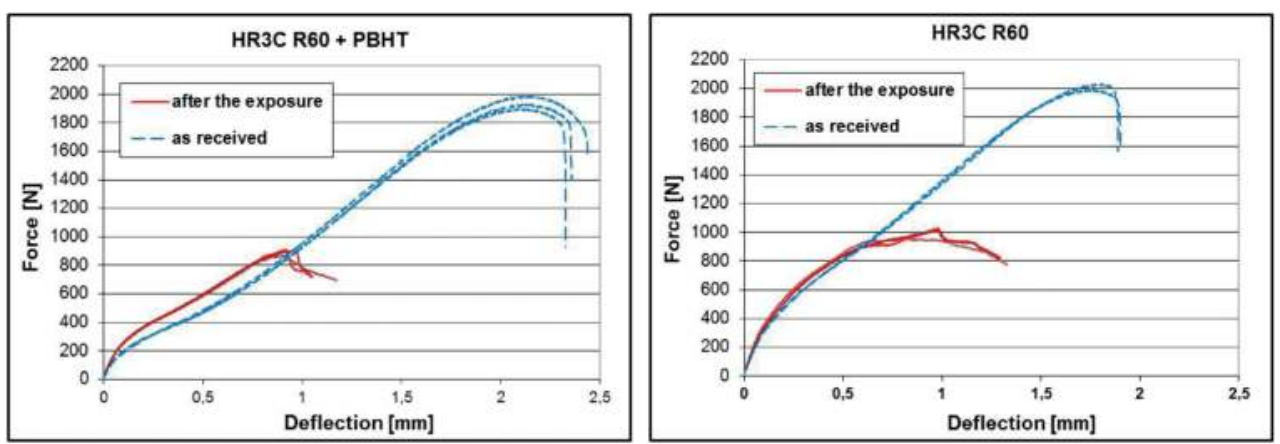

Figure 13. Force versus displacement of tube bend HR3C in as-bended state and after exposure. 

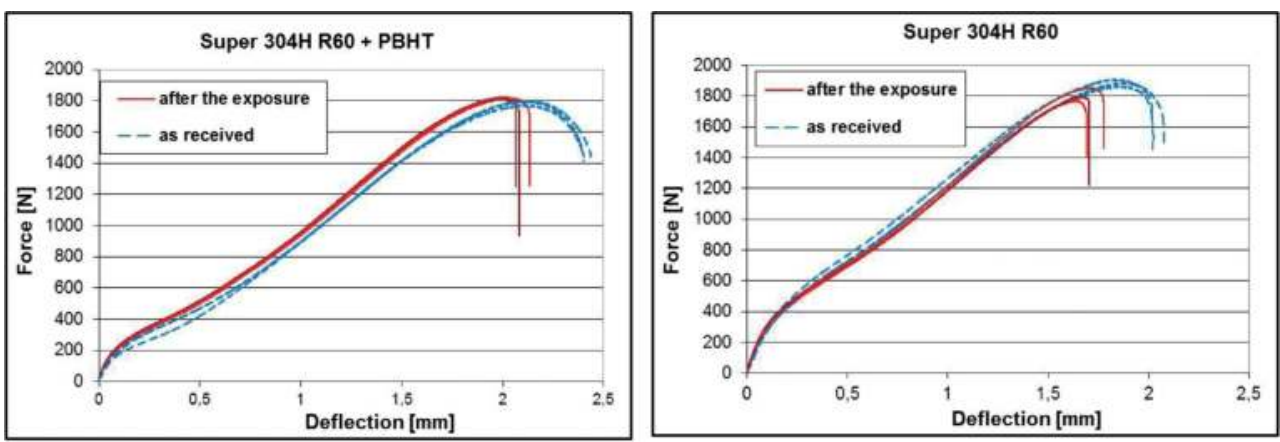

Figure 14. Force versus displacement of tube bend Super $304 \mathrm{H}$ in as-bended state and after exposure.

bend and the deformation energy seems to decrease the activation energy of $\sigma$-phase formation. Therefore, samples with PBHT and samples with large bend radii and relaxed or lower internal stresses, show only small, if any, content of $\sigma$-phase.

\section{Importance of heat treatment of tube bends - when is HT necessary?}

Based on experimental investigations mentioned above the tube bends with low bending radii (R60, R80) require heat treatment after bending to minimize internal residual stresses and tendency for precipitation of $\sigma$-phase in the structure. If the exposure temperature is higher than $700^{\circ} \mathrm{C}$, it is necessary to apply heat treatment after bending even for bending radii R100.

After exposure in temperature range $635-694^{\circ} \mathrm{C}$ small amount of $\sigma$-phase was found in all specimens near the surfaces. After exposure in temperature range $726-775^{\circ} \mathrm{C} \sigma$-phase was found across the whole wall thickness of extrados. In order to minimize the volume of $\sigma$-phase in the structure of extrados with small bend radii, it is necessary to carry out solution annealing after bending [28].

\section{Degradation of material properties due to sigma phase in power plant tubes after 100,000 $\mathrm{h}$ of exposure}

Very little data describing long-term exposure of TP347HFG and TP347H is available in the literature. Although there are many articles on short-term laboratory exposure and initial experience in power plants. The Danish coal-fired ultra-super critical (USC) plant, Nordjyllandsværket, after 100,000 h of operation has focused on the state of materials, such as P 91 or TP347HFG used in the boiler. Tube sections were removed from more than 20 different locations in the boiler during the 2012 summer shutdown to assess the material conditions in the boiler. The boiler was designed as an USC once-through Benson tower type with double reheat and was commissioned in 1998 with 290 bar and $580 / 580^{\circ} \mathrm{C}$ steam data [32]. 


\begin{tabular}{|c|c|c|c|c|c|c|}
\hline \multirow[t]{2}{*}{ Tube } & \multirow[t]{2}{*}{ Location in the boiler } & \multirow[t]{2}{*}{ Material } & \multicolumn{2}{|c|}{$\sigma$-phase (\%) } & \multirow{2}{*}{$\begin{array}{l}\text { Temperature of } \\
\text {-exposure }\left({ }^{\circ} \mathrm{C}\right)\end{array}$} & \multirow{2}{*}{$\begin{array}{l}\text { ASTM grain } \\
\text { size G }\end{array}$} \\
\hline & & & $0^{\circ}$ & $180^{\circ}$ & & \\
\hline 10 & Outlet SH1 & TP347HFG & - & - & 585 & $7-9$ \\
\hline 11 & Outlet RH2.2 & TP347HFG & - & - & 600 & $6-8$ \\
\hline 13 & SH1 middle & ТР347H & 1.1 & 0.2 & 585 & $7-8$ \\
\hline 14 & Outlet RH1.2 & TP347HFG & 1.6 & 0.6 & 590 & $7-8$ \\
\hline 15 & Outlet SH2 & TP347HFG & 1.2 & - & 600 & $6-8$ \\
\hline 16 & Inlet SH2 & TP347HFG & 1.4 & 0.2 & 620 & $7-9$ \\
\hline 17 & Inlet RH1.2 & TP347HFG & 5.5 & 0.6 & $585 / 570$ & $7-9$ \\
\hline 18 & Inlet SH1 & ТР347H & 0.8 & - & 535 & 8 \\
\hline 19 & Inlet SH1 & TP347H & 2.2 & - & $550 / 535$ & $8-9$ \\
\hline 20 & Outlet Screen & TP347HFG & 1.1 & 0.2 & $570 / 555$ & $5-8$ \\
\hline 21 & Outlet Screen & TP347HFG & - & - & $570 / 555$ & $5-8$ \\
\hline
\end{tabular}

Table 3. Area fraction of sigma phase in TP347H and TP347HFG tubes [32].

The tubes have been investigated in order to document the residual wall thickness, fire-side corrosion and streamside oxidation rates and morphology and microstructure evolution after $100,000 \mathrm{~h}$ of exposure. This assessment has revealed the presence of $\sigma$-phase in superheater $(\mathrm{SH})$ and reheater $(\mathrm{RH})$ tubes.

It is well-known that the orientation of tubes in the boiler has a great influence on the microstructure. Therefore, the fire-side facing the hot flue gas was marked as position $0^{\circ}$ and the opposite side was marked $180^{\circ}$ (see Table 3). Table 3 also shows amount of $\sigma$-phase identified using SEM in various tubes.

\section{Mechanical testing}

Tensile strength seemed to be quite comparable in all tubes regardless of the position, that is, regardless of the content of $\sigma$-phase. On the other hand, yield strength at the position $0^{\circ}$ was lower in tubes that contained higher amounts of $\sigma$-phase (tubes 17 and 19) and also in tube 13 , which contained small amount of $\sigma$-phase, but was operated at the higher temperature $\left(585^{\circ} \mathrm{C}\right)$, see Table 4 .

Although strength seemed not to be affected by $\sigma$-phase appearance, plastic properties, such as elongation and reduction of area, showed a significant response. The presence of $\sigma$-phase resulted in a higher loss of elongation and reduction of area. The measured values of elongation and reduction of area can be directly related to toughness of steel as $\sigma$-phase appears to change the fracture properties. Nearly all investigated tubes showed decrease of elongation and reduction of area (8-25\% depending on the content of $\sigma$-phase) compared to tubes without $\sigma$-phase. 


\begin{tabular}{|c|c|c|c|c|c|}
\hline \multirow[t]{2}{*}{ Tube } & \multirow[t]{2}{*}{ Specimen ID } & Tensile strength & Yield strength & Elongation & Reduction of area \\
\hline & & \multicolumn{2}{|l|}{ (MPa) } & \multicolumn{2}{|l|}{$(\%)$} \\
\hline \multirow[t]{4}{*}{17} & \multirow[t]{2}{*}{ Position $180^{\circ}$} & 675 & 357 & 48.0 & 64.0 \\
\hline & & 684 & 389 & 43.3 & 59.6 \\
\hline & \multirow[t]{2}{*}{ Position $0^{\circ}$} & 676 & 277 & 38.7 & 45.9 \\
\hline & & 678 & 286 & 38.7 & 45.5 \\
\hline \multirow[t]{4}{*}{19} & \multirow[t]{2}{*}{ Position $180^{\circ}$} & 696 & 343 & 47.3 & 73.2 \\
\hline & & 697 & 347 & 50.0 & 73.3 \\
\hline & \multirow[t]{2}{*}{ Position $0^{\circ}$} & 685 & 300 & 42.7 & 55.4 \\
\hline & & 684 & 301 & 41.0 & 55.4 \\
\hline \multirow[t]{4}{*}{13} & \multirow[t]{2}{*}{ Position $180^{\circ}$} & 715 & 374 & 51.3 & 71.6 \\
\hline & & 716 & 379 & 50.3 & 71.5 \\
\hline & \multirow[t]{2}{*}{ Position $0^{\circ}$} & 700 & 331 & 46.7 & 60.9 \\
\hline & & 700 & 337 & 44.7 & 60.9 \\
\hline
\end{tabular}

Table 4. Results of tensile test of tube with maximum content of $\sigma$-phase.

Although the presence of brittle phase in the structure cannot be unambiguously indicated by tensile testing, it could be clearly identified by drop in fracture energy during Charpy-V notch testing. The presence of $\sigma$-phase in the test sample resulted in drop of impact energy in all tested tubes, Figure 15. Even though the absolute values of impact energy between thin-walled and thick-walled tubes cannot be directly compared due to various specimen size, the difference between position 0 and $180^{\circ}$ is clearly visible. The only exception is the tube 14 , which contains the smallest amount of $\sigma$-phase. The decrease of the impact energy due to high temperature exposure and $\sigma$-phase precipitation is illustrated also in Figure 15, where the last green columns represent the impact energy in TP347HFG tubes in the as-received condition [32, 33].

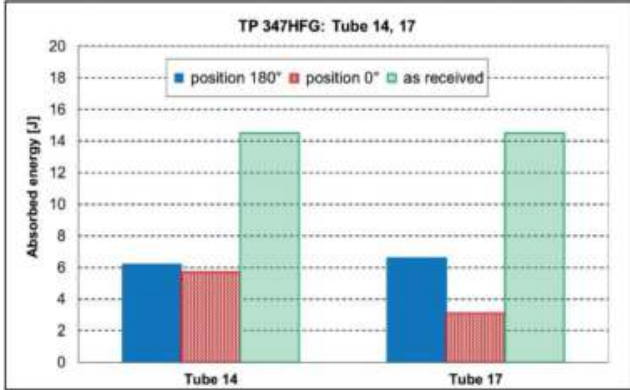

a)

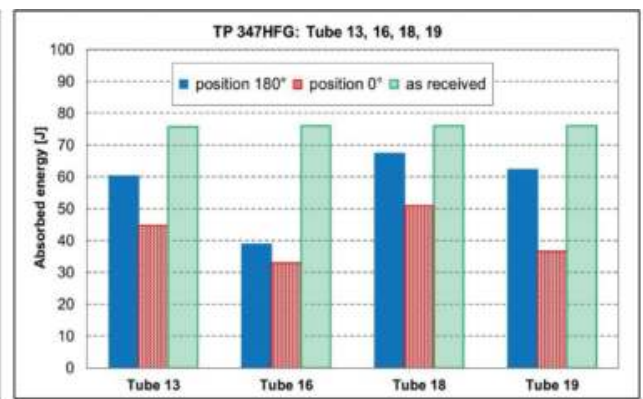

b)

Figure 15. Absorbed energy at the side with (position $0^{\circ}$ ) and without $\sigma$-phase (position $180^{\circ}$ ) and in as-received condition tubes with wall thickness $3.6 \mathrm{~mm}$ miniaturized Charpy V specimens $5 \times 3 \times 32 \mathrm{~mm}$ (a) and tubes with wall thickness higher than $7 \mathrm{~mm}-$ subsize Charpy-V specimens $10 \times 5 \times 55 \mathrm{~mm}$ (b). 


\section{Metallographic and fractographic investigations of sigma phase}

In order to get a general overview of the microstructural changes and to quantify the amount of $\sigma$-phase, all samples were investigated by light optical microscopy (LOM) and by scanning electron microscopy (SEM). ASTM grain size was also measured, see Table 3.

Larger amount of $\sigma$-phase was found in position $0^{\circ}$, that is, on the fire-side. The $\sigma$-phase free band of about $300-400 \mu \mathrm{m}$ at the surface on the flue gas side was observed. The greatest concentration of $\sigma$-phase was found in the mid-thickness of the tubes with decreasing concentration toward the inner surface of the tubes. Small amount of $\sigma$-phase was observed also in position $180^{\circ}$ that is partially shielded from the hot flue gas by surrounding tubes [25]. Figure 16 shows the difference in $\sigma$-phase content in position 0 and $180^{\circ}$ for sample with the maximum content of $\sigma$-phase.

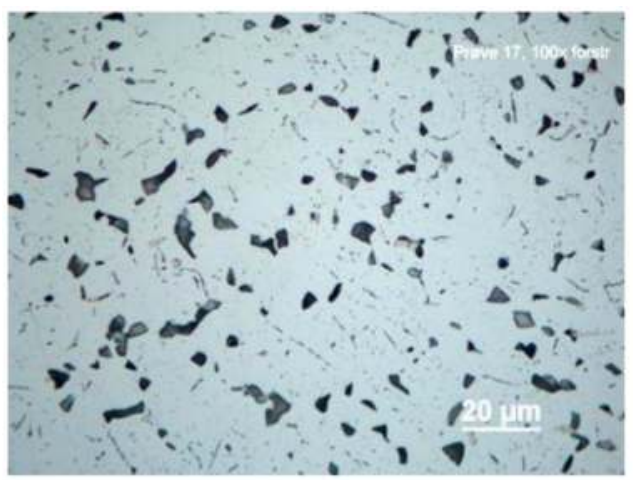

a)

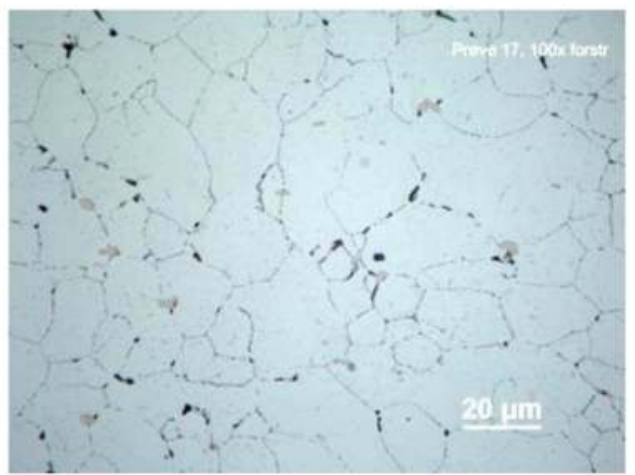

b)

Figure 16. Tube17: position $0^{\circ}-5.5 \%$ of sigma phase (a), position $180^{\circ}-0.6 \%$ of $\sigma$-phase (b).

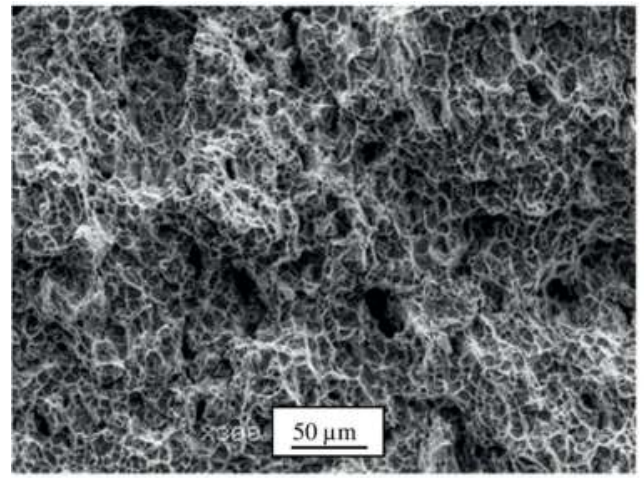

a $(300 x)$

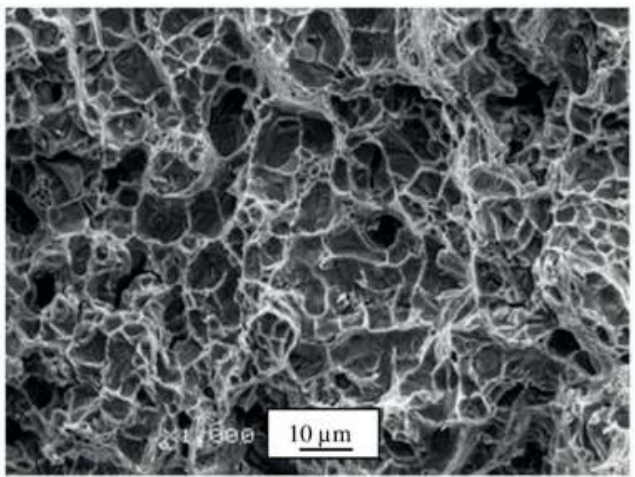

$\mathrm{b}(1000 \mathrm{x})$

Figure 17. Tube 17: position $0^{\circ}$ (high content of $\sigma$-phase) combined ductile/brittle fracture mode (a) and detailed image of brittle cleavage facets connected by ductile tearing ridges (b). 


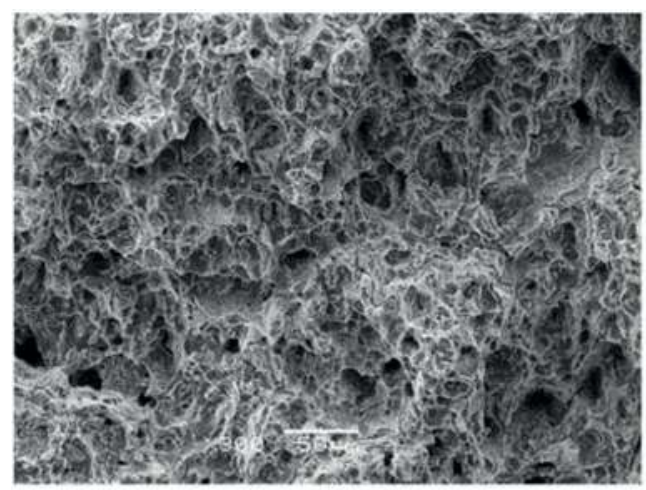

a $(300 x)$

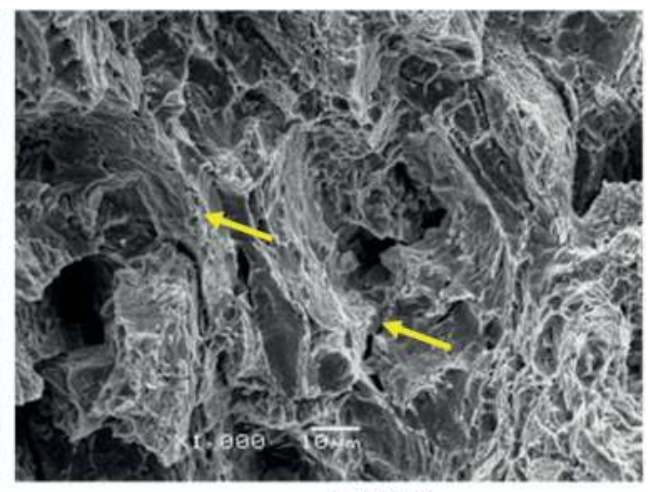

b (1000x)

Figure 18. Tube 17 : position $180^{\circ}$ (without $\sigma$-phase) combined ductile/brittle fracture mode (a) and detailed image of the transgranular ductile fracture and holes with particles (marked with red arrows) (b).

Drop of fracture energy due to $\sigma$-phase has become evident on the fracture surface. The fractographic analysis performed on the surfaces of miniaturized Charpy specimens revealed significant differences in the morphology of fracture surfaces and these differences qualitatively corresponded to different values of impact energy observed in both cases (Figures 17 and 18).

\section{Small punch testing}

Another way how to cope with the fact that tensile test cannot respond to $\sigma$-phase presence in the microstructure is application of small punch test method. Figure 19 shows comparison of test records (force versus displacement) of the SPT specimens from both sides of the tube 17 containing the highest amount of $\sigma$-phase. Five SPT specimens were prepared from each side of tube in order to obtain the information about the scatter of results. The difference between the side with and without $\sigma$-phase can be imagined as the area under the curves representing fracture energy. The drop of fracture energy between both sides of one tube was about $50 \%$.

The values of fracture energy of all tested tubes are shown in Figure 20, where the test results are complemented by the values of fracture energy of TP347HFG steel in as-received condition [32]. In this way, it was possible to compare both the effect of $\sigma$-phase and the effect of operation conditions on fracture behavior of the steel under investigation. It was assumed that the difference between position 0 and $180^{\circ}$ represented the effect of $\sigma$-phase in the structure after long-term operation at high temperature.

The surprising result of this testing was the fact that the fine-grained tubes $(14,16,17)$ are more sensitive to the presence of $\sigma$-phase in the structure than coarse-grained tubes $(13,18,19)$. It seems that the coarse-grained tubes are more resistant to embrittlement effect of $\sigma$-phase than the fine-grained tubes. This result is in great contradiction to the widely published statement about the higher embrittlement of coarse-grained material due to $\sigma$-phase precipitation. 
TP 347H: Tube 17

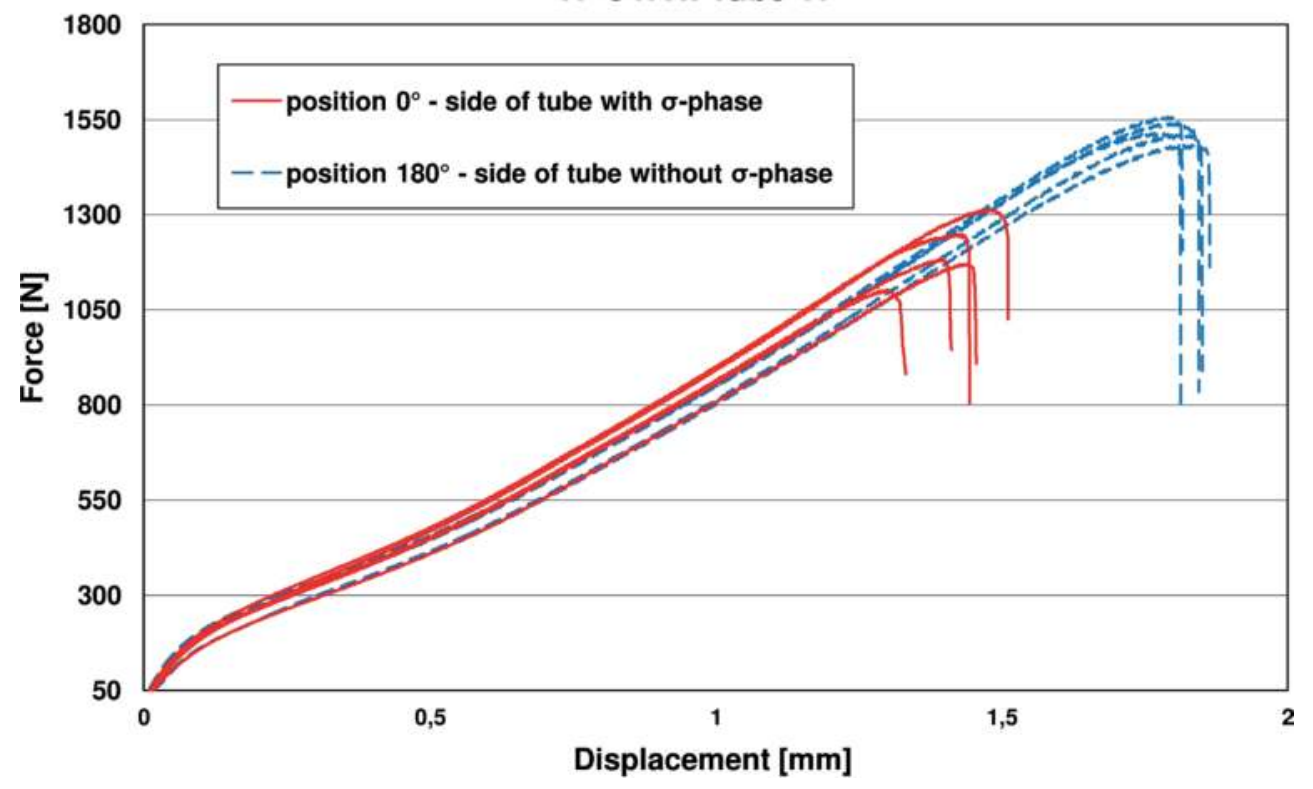

Figure 19. Comparison of absorbed fracture energy during SPT testing of tube 17 at position 0 and $180^{\circ}$.

TP $347 \mathrm{H}$ Tube $13,14,16,18,19$

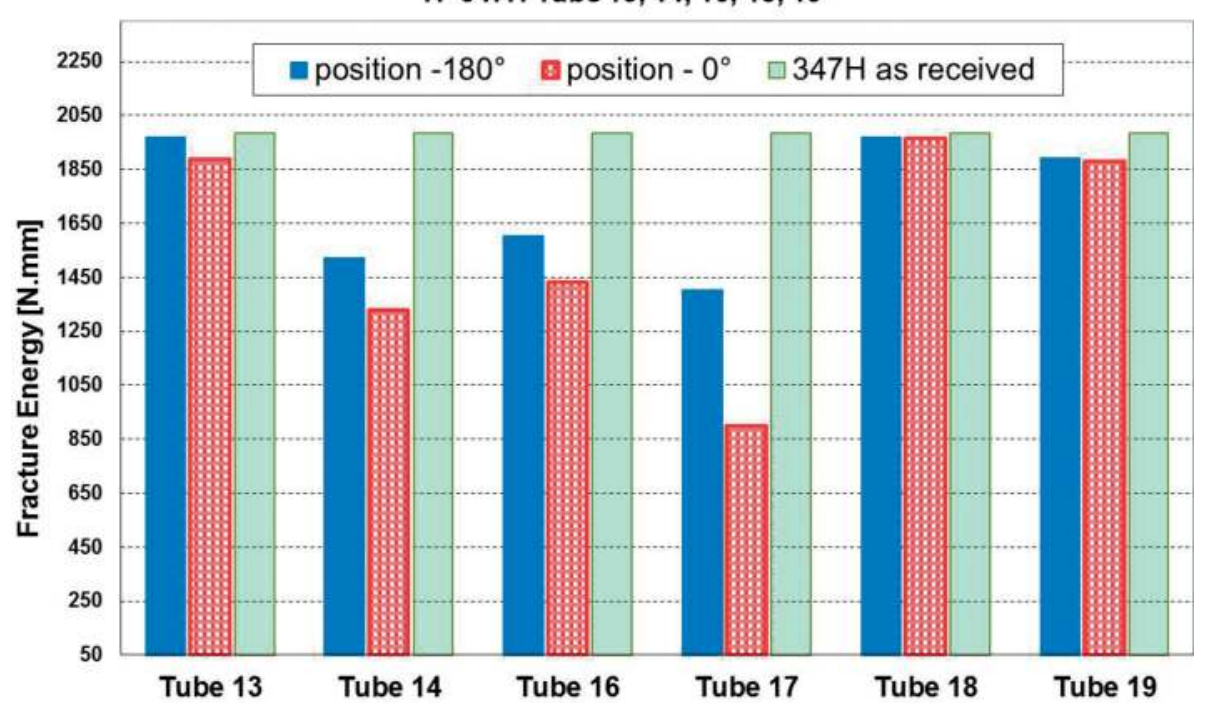

Figure 20. Fracture energy of tube position 0 and $180^{\circ}$ and as-received state. 
All the performed experiments thus confirmed that $\sigma$-phase precipitated in the tube bends of advanced heat-resistant austenitic steels for USC conditions after 1 year of high temperature exposure without any external loading. The strong embrittlement effect of $\sigma$-phase was clearly confirmed by drop of fracture energy of small punch tests. Cold work, which stores the deformation energy in the microstructure, accelerates the precipitation of $\sigma$-phase. However, this effect can be eliminated by the post-bend heat treatment.

The negative effect of sigma phase on fracture energy of TP347HFG can clearly be seen from results obtained by evaluation of microstructure and mechanical properties of superheater tubes made of TP347HFG grade after exposure high temperatures for 100,000 h in a USC plan, where the amount of $\sigma$-phase was measured to be about $5 \%$.

\section{Creep properties and structural changes of base material and welded joints of advanced austenitic steels}

Tubes $\varnothing 38 \times 6.3 \mathrm{~mm}$ made from steels Super $304 \mathrm{H}$ and HR3C were used for the evaluation of creep properties of the tubes and their welded joints. The circumferential tube joints were performed by GTAW (method 141) automated orbital welding (position PK), where both ends of the tube are centered in horizontal position and do not move during welding. Generally, welding of all austenitic steels must be performed with restricted thermal input in order to avoid hot cracking of weldments. Heat input for individual layers was therefore in the range from 1100 to $1900 \mathrm{~J} / \mathrm{mm}$ and interpass temperature was kept at $150^{\circ} \mathrm{C}$. Welding wires $\varnothing 0.8 \mathrm{~mm}$ were used for welding. A matching filler metal Thermanit $304 \mathrm{HCu}$ was used for homogeneous weld joints of Super $304 \mathrm{H}$ steel, whereas overmatching nickel-based alloy filler metals Thermanit 617 and UTP A6170Co were used for homogeneous weld joint of HR3C steel. The chemical compositions of the filler metals are shown in Table 5 [34].

Stress rupture tests of both base materials and welded joints performed at temperatures 650, 700 and $750^{\circ} \mathrm{C}$. The calculated values of $10,000 \mathrm{~h}\left(\mathrm{R}_{\mathrm{u} / \mathrm{T} / 10}{ }^{4}\right)$ creep rupture strength are stated in Table 6. The calculation was performed using Seifert parametric equation [35]:

$$
\log R_{u T}=A_{0}+A_{1} P+A_{2} P^{2}, \text { where } P=\left[T\left(C+\log t_{r}\right)\right] 10^{-4}
$$

where $T$ is the absolute temperature in $\mathrm{K}, t_{r}$ is time to fracture in hours, $A_{1^{\prime}} A_{2^{\prime}} A_{k}$ and $C$ are material constants.

\begin{tabular}{llllllllllllll}
\hline Filler metal & $\mathbf{C}$ & $\mathrm{Si}$ & $\mathbf{M n}$ & $\mathbf{C u}$ & $\mathbf{M o}$ & $\mathrm{Cr}$ & $\mathbf{N i}$ & $\mathrm{Ti}$ & $\mathrm{Fe}$ & $\mathrm{Nb}$ & $\mathrm{Al}$ & $\mathbf{N}$ & $\mathbf{C o}$ \\
\hline Thermanit 304HCu & 0.10 & 0.4 & 3.2 & 3.0 & 0.8 & 18.0 & 16.0 & - & - & 0.4 & - & 0.2 & - \\
Thermanit 617 & 0.05 & 0.1 & 0.1 & - & 9.0 & 21.5 & rest & 0.5 & 1.0 & - & 1.0 & - & 11.0 \\
UTP A 6170 Co & 0.06 & 0.3 & - & - & 8.5 & 22.0 & rest & 0.4 & 1.0 & - & 1.0 & - & 11.5 \\
\hline
\end{tabular}

Table 5. Nominal chemical composition of filler materials, wt.\% [34]. 


\begin{tabular}{lllllll}
\hline Steel & Super $\mathbf{3 0 4 H}$ & \multicolumn{5}{l}{ HR3C } \\
\hline Temperature & $650^{\circ} \mathrm{C}$ & $700^{\circ} \mathrm{C}$ & $750^{\circ} \mathrm{C}$ & $650^{\circ} \mathrm{C}$ & $700^{\circ} \mathrm{C}$ & $750^{\circ} \mathrm{C}$ \\
Tube & 174 & 104 & 60 & 168 & 104 & 62 \\
Weldment & 155 & 95 & 60 & 141 & 99 & 70 \\
Datasheet & 160 & 101 & 61 & 174 & 106 & 64 \\
SRF (-) & 0.89 & 0.91 & 1.00 & 0.84 & 0.95 & 1.00 \\
\hline
\end{tabular}

Table 6. Creep rupture stress $\mathrm{R}_{\mathrm{u} / \mathrm{T} / 10}{ }^{4}$ of the Super $304 \mathrm{H}$ and HR3C steel tubes and weldments, MPa.

Table 6 shows also the results of calculation of strength reduction factor (SRF) expressing the ratio of creep rupture strength of welded joints $R_{u}(W)$ and the creep strength of base metal $R_{u}(B M)$, that depends on the temperature and time to rupture [36]:

$$
S R F=\frac{R_{u}(W)}{R_{u}(B M)}=f(t, T) \leq 1
$$

Recalculation of experimental results into the value of Larson-Miller parameter $P_{L M}$ was used to compare the evaluated creep resistance of the base metal and welded joint in the Eq. (4) [37]:

$$
P_{L M}=T[\log (t)+C]
$$

with the usual meanings of the variables. Constants $C$ equals to 20.8 in Super $304 \mathrm{H}$ and 16.8 in HR3C, which are the values calculated using least squares method from stress rupture data stated in material sheets [38,39].

Creep rupture strength as well as creep behavior of both steels is very similar, their strength reduction factor increases with increasing temperature and at $700^{\circ} \mathrm{C}$ creep rupture strength of welded joint overcomes that for base metal and SRF equals to one. Similar behavior was observed also in other tested welded joints of Super 304H steel [40]. Literature data show that and this type of behavior is typical for nearly all austenitic heat-resistant steels [41-43].

The comparison of creep tests of the tubes and weldment of Super 304H and HR3C steels is shown in Figure 21, base metal (dark symbols) and welded joints (light symbols). Still running stress rupture tests are marked by red arrows. The solid lines labeled WB 550 and WB 47 represent the average creep rupture strength of steels Super $304 \mathrm{H}$ according to Ref. [38] and HR3C according to Ref. [39], the dashed lines then correspond to the lower $-20 \%$ tolerance limit. All the results confirmed good creep resistance of the tested tubes as well as their weld joints.

However, the danger of $\sigma$-phase precipitation in the steel does not lie in lowering the creep strength but in exhausting of plasticity and embrittlement of the structure. This phenomenon can be clearly seen in Figure 22, showing the dependence of reduction of area on LarsonMiller parameter in both basic material and weldments. 

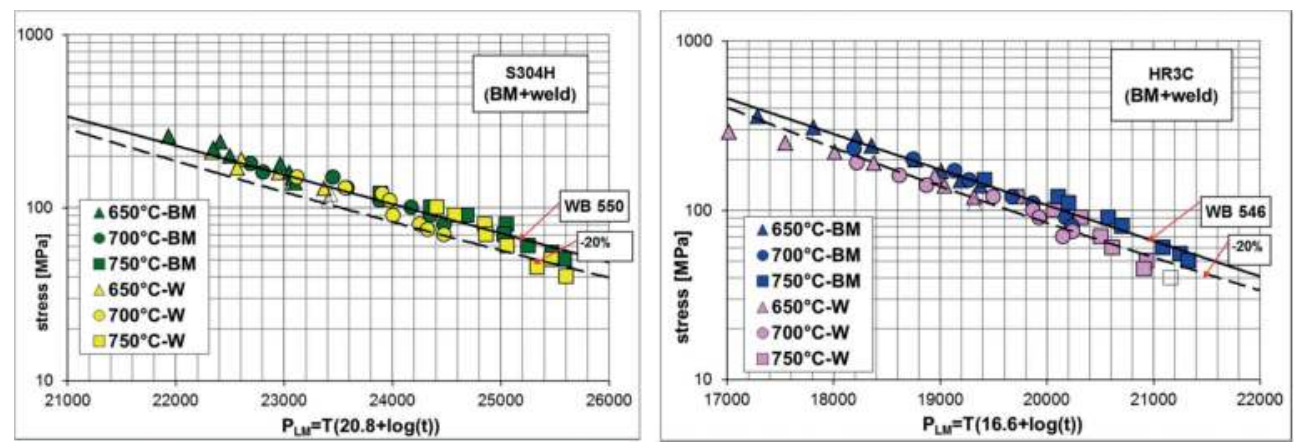

Figure 21. Dependence of stress on L-M parameter of Super 304H and HR3C steels and their weldments.

Plasticity drop in stainless steels at room temperature associated with precipitation of $\sigma$-phase is a well-known phenomenon. However, $\sigma$-phase seems to precipitate in shorter time and the drop of reduction of area seems to be deeper than that observed in austenitic heat-resistant steels of 304, 316, 321 and 347 types formerly used for the outer parts of superheaters of supercritical boilers.

The structural change and the form and extent of the $\sigma$-phase precipitation during creep exposure can be demonstrated on the example of above mentioned circumferential welds on tubes made of HR3C steel where structural states are compared here, in the as-welded state and after creep exposure at $750^{\circ} \mathrm{C} / 50 \mathrm{MPa}$ for $7704 \mathrm{~h}$.

In the as-welded state the microstructure of the base metal of the welded joint close to the fusion line consisted of austenitic grains of various size (Figure 23). The microstructure of the nickel-based weld metal is documented in Figure 24. The austenitic structure contained relatively large primary carbides inside the grains, but no carbides were present at the grain boundaries of base material (Figures 25 and 26).
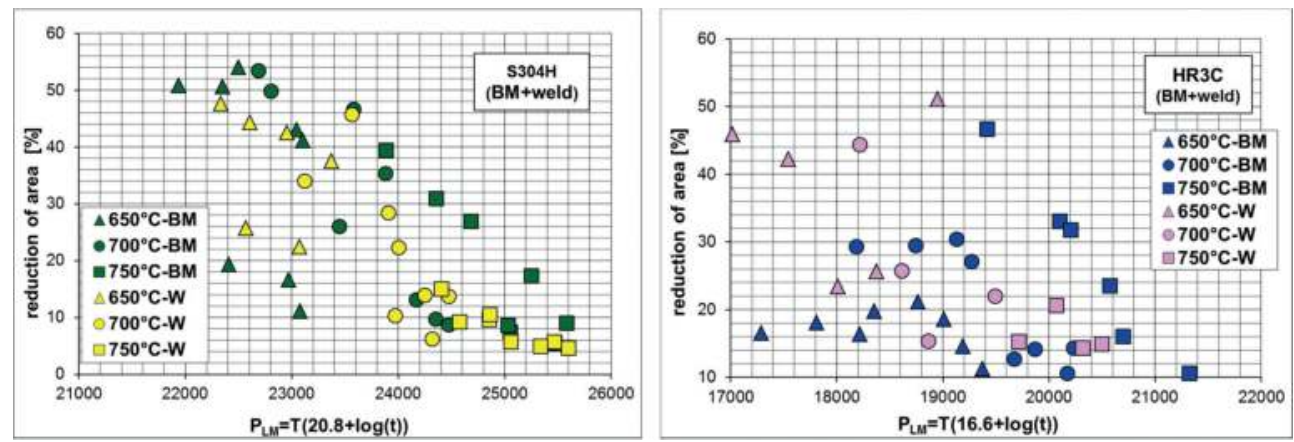

Figure 22. Dependence of reduction of area on L-M parameter of Super 304H and HR3C steels and their weldments. 


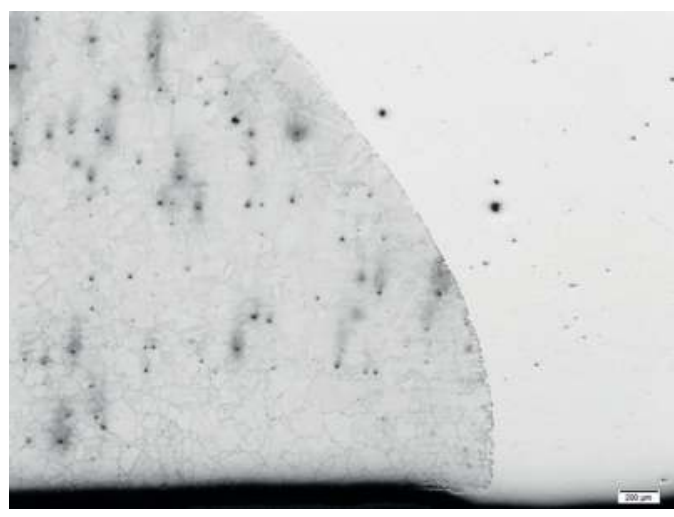

Figure 23. Microstructure of the root part of welded tube made of steel HR3C.

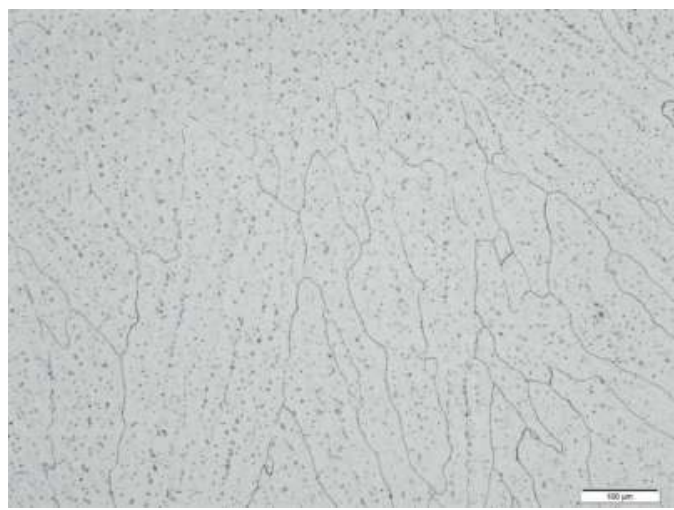

Figure 24. Microstructure of weld metal (Thermanit 617).

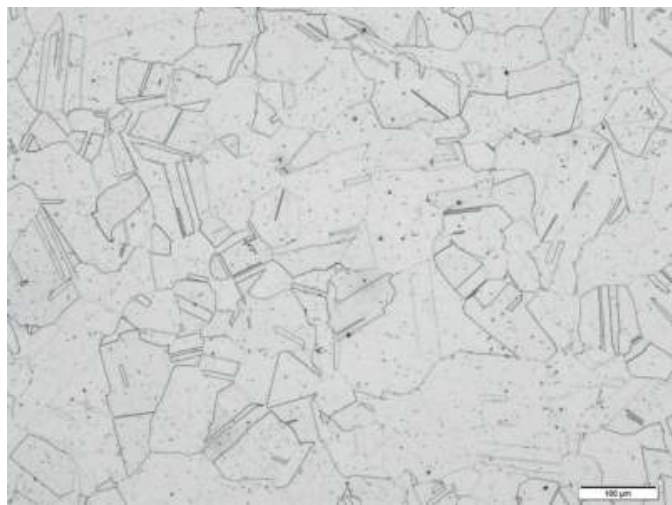

Figure 25. Microstructure of base material. 


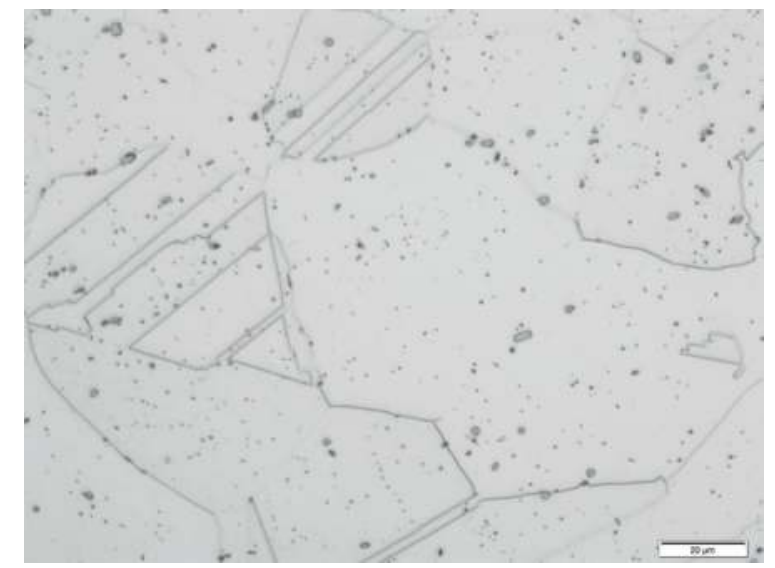

Figure 26. Detail of microstructure of base material.

The final rupture of the analyzed creep specimen started in the fusion line and propagated through the coarse-grained part of heat-affected zone (Figures 27 and 28). The failure was brittle, mostly intergranular and the reduction of area was very low, only $2.8 \%$. Even though $\sigma$-phase precipitated in the base material, too, it formed randomly distributed particles that are not so dangerous as a network of $\sigma$-phase particles along grain boundaries detected in the coarse-grained HAZ, compare Figures 29 and 30.

The microstructural analysis thus confirmed the correlation between low plasticity of steel after long-term creep exposure at high temperatures and precipitation of $\sigma$-phase on grain boundaries of austenite. Especially in welded joints precipitation in the form of network on grain boundaries can lead to the type III cracking, that is, failure in the coarse-grained part of heat-affected zone close to the fusion line. This part of heat-affected zone is overheated during welding and accompanying grain growth will reduce the number of grains and the length of grain boundaries. Precipitating $\sigma$-phase along grain boundaries can form more or less continuous network and further reduce plasticity of this part of heat-affected zone that has due to its microstructure high, creep strength but very low toughness and plasticity.

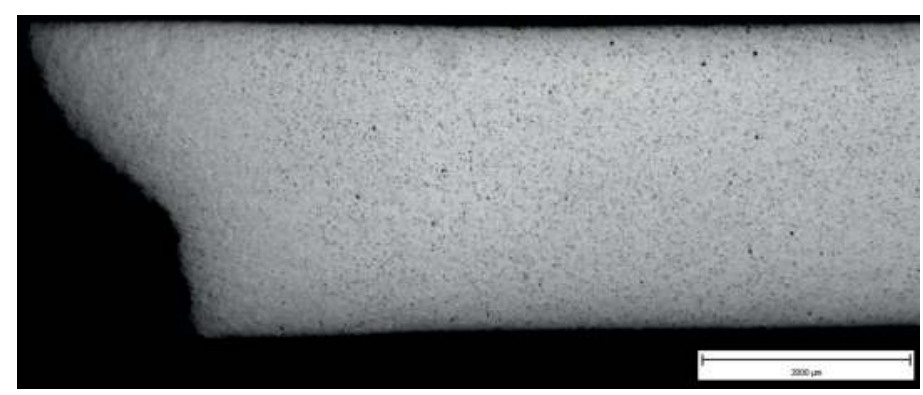

Figure 27. Macrostructure of failure location of creep specimen tested at $750^{\circ} \mathrm{C} / 7704 \mathrm{~h}$. 


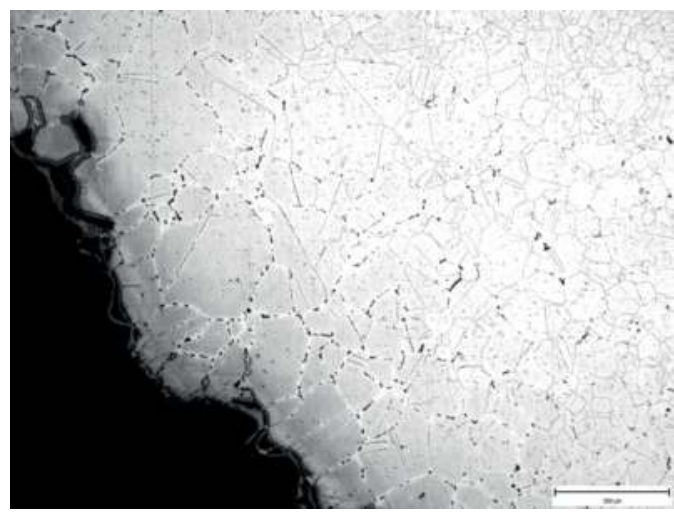

Figure 28. Microstructure of coarse-grained $\mathrm{HAZ}$ (etched in $\mathrm{KOH}$ ).

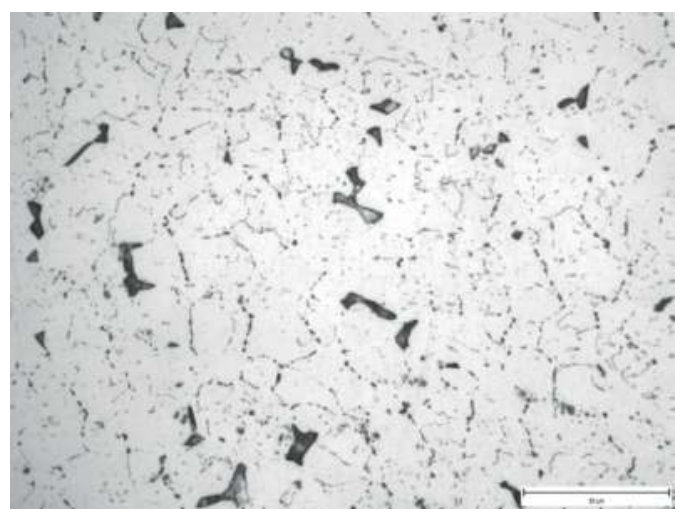

Figure 29. Detail of $\sigma$-phase particles in the base metal (etched in $\mathrm{KOH})$.

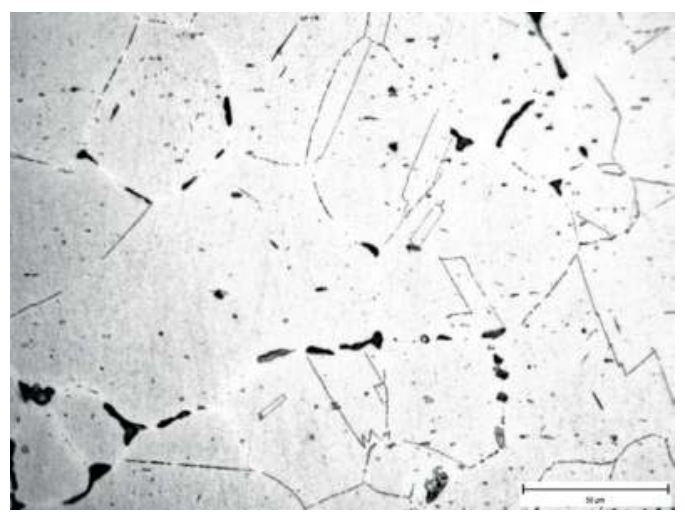

Figure 30. Detail of network of $\sigma$-phase along grain boundaries in coarse-grained HAZ (etched in $\mathrm{KOH}$ ). 


\section{Conclusions}

High temperature and long-term exposure of all heat-resistant steels in USC and advanced ultra-super critical (A-USC) boilers brings about advanced demands for their structural stability. Increased operating temperatures accelerate all degradation processes that appear in all types of heat-resistant steels, from low-alloy through chromium modified toward austenitic stainless steels. Precipitation of $\sigma$-phase represents one of the most potentially dangerous degradation mechanism in advanced austenitic heat-resistant steels. Although precipitation of this phase was observed after long-term exposure at high temperatures in many austenitic steels, the results obtained during testing of superheater tubes and their bends as well as welded joint have shown that the precipitation of $\sigma$-phase starts in these steel grades after few thousands of high temperature exposure and even without external loading. Stress and plastic deformation induced in the material during cold bending and/or welding can further accelerate the commencement of its precipitation. Although there are developed also steels intentionally precipitation strengthened by $\sigma$-phase [44], the results obtained on three advanced austenitic heat-resistant steel grades Super 304H, HR3C and TP347HFG have proved the detrimental effect of $\sigma$-phase precipitation namely on toughness and plasticity of these steels.

\section{Acknowledgements}

This chapter was created in the Project No. LO1203 "Regional Materials Science and Technology Centre-Feasibility Program" funded by the Ministry of Education, Youth and Sports of the Czech Republic.

\section{Author details}

Zdeněk Kuboň*, Šárka Stejskalová and Ladislav Kander

*Address all correspondence to: creep.lab@mmvyzkum.cz

Material \& Metallurgical Research, Ltd., Vítkovice, Ostrava, Czech Republic

\section{References}

[1] Viswanathan R, Purgert R, Rao U. Materials Technology for Advanced Coal Power Plants. Proceedings of the 1st Int. Conference on Super-High Strength Steels. Associazione Italiana di Metallurgia; Rome; 2005

[2] Masuyama F. Steam plant material developments in Japan. In: Lecomte-Beckers J et al., editors. Materials for Advanced Power Engineering, Part III. Forschungszentrum Juelich, Juelich; 1998. p. 1807-1824 
[3] Larsen $\mathrm{OH}$. Austenitic steels-mechanical properties, exfoliation, availability. In: Material and Quality Assurance. VGB Workshop; May 13-15; Copenhagen; 2009. p. Doc. no 541576

[4] Chi C, Yu H, Xie X. Advanced austenitic heat-resistant steels for ultra-super-critical (USC) fossil power plants. In: Alloy Steel-Properties and Use. Rijeka, Croatia: InTech; 2011. ISBN 978-953-307-484-9

[5] Duhaj P, Ivan J, Makovicky E. Sigma phase precipitation in austenitic steels. JISI. 1968; 206:1245-1252

[6] Wilms ME, Gadgil VJ, Krougman JM, Ijsseling FP. The effect of $\sigma$-phase precipitation at $800^{\circ} \mathrm{C}$ on the corrosion resistance in sea-water of a high alloyed duplex stainless steel. Corrosion Science. 1994;36(5):871-881

[7] Souza CM, HFG A, SSM T, JMA R. The $\sigma$ phase formation in annealed UNS S31803 duplex stainless steel: Texture aspects. Materials Characterization. 2008;59:1301-1306

[8] Sasikala G, Ray SK, Mannan SL. Kinetics of transformation of delta ferrite during creep in a type $316(\mathrm{~N})$ stainless steel weld metal. Materials Science and Engineering A. 2003;359(1):86-90

[9] Barcik J. Mechanism of $\sigma$-phase precipitation in Cr-Ni austenitic steels. Materials Science and Technology. 1988;4:5-15

[10] Hsieh CC, Wu W. ISRN overview of intermetallic sigma phase precipitation in stainless steels. Metallurgy. 2012;2012

[11] Woodyatt LR, Sims CT, Heattie HJ. Prediction of sigma type phase occurrence from compositions in austenitic superalloys. Transactions of the Metallurgical Society of the American Institute of Mechanical Engineers. 1966;236:519-527

[12] Guan $\mathrm{K}, \mathrm{Xu} \mathrm{X}, \mathrm{Xu} \mathrm{H}$, Wang Z. Effect of aging at $700^{\circ} \mathrm{C}$ on precipitation and toughness of AISI 321 and AISI 347 austenitic stainless steel welds. Nuclear Engineering and Design. 2005;235:2485-2494

[13] Liu F, Hwang YH, Nam SW. The effect of post weld heat treatment on the creep-fatigue behavior of gas tungsten arc welded 308L stainless steel. Materials Science and Engineering A. $2006 ; 427: 35-41$

[14] Chen TH, Yang JR. Effects of solution treatment and continuous cooling on $\sigma$-phase precipitation in a 2205 duplex stainless steel. Materials Science and Engineering A. 2001;311:28-41

[15] Restrepo Garcés G, Le Coze J, Garin JL, Mannheim RL. $\sigma$-Phase precipitation in two heat-resistant steels-Influence of carbides and microstructure. Scripta Materialia. 2004; 50(5):651-654

[16] Redjaimia A, Metauer G, Gantois M. Decomposition of Delta ferrite in a Fe-22Cr-5Ni3Mo-0.03C duplex stainless steel. A morphological and structural study. In: Proceedings of Duplex Stainless Steels, Vol. 1; Beaune, France. 1991. p. 112-126 
[17] Wasnik DN, Dey GK, Kain V, Samajdar I. Precipitation stages in a 316L austenitic stainless steel. Scripta Materialia. 2003;49:135-141

[18] Villanueva DME, Junior FCP, Plaut RL, Padilha AF. Comparative study on sigma phase precipitation of three types of stainless steels: Austenitic, superferritic and duplex. Materials Science and Technology. 2006;22(9):1098-1104

[19] Shinohara K, Seo T, Kumada K. Recrystallization and sigma phase formation as concurrent and interacting phenomena in $25 \% \mathrm{Cr}-20 \% \mathrm{Ni}$ steel. Materials Transactions. 1979; 20(12):713-723

[20] Baerlecken E, Fabritius H. Umwandlungskinetik der sigmaphase in einer Eisen-ChromLegierung mit 48\% Chrom. Arch Eisenhuttenwes. 1955;26:679-686

[21] Garzón CM, Ramirez AJ. Growth kinetics of secondary austenite in the welding microstructure of a UNS S32304 duplex stainless steel. Acta Materialia. 2006;54(12):3321-3331

[22] Weiss B, Stickler R. Phase instabilities during high temperature exposure of 316 austenitic stainless steel. Acta Metallurgica. 1972;3(4):851-866

[23] Minami Y, Kimura H, Ihara Y. Microstructural changes in austenitic stainless steels during long-term aging. Materials Science and Technology. 1986;2:795-806

[24] Schwind M, Kallqvist J, Nilsson J-O, Agren J, Andren H-O. $\sigma$-phase precipitation in stabilized austenitic stainless steels. Acta Materialia. 2000;48:2473-2481

[25] Sourmail T, Bhadeshia HKDH. Modelling simultaneous precipitation reactions in austenitic stainless steels. CALPHAD. 2003;27:169

[26] Joseph R. Davis Ed., editor. ASM Specialty Handbook: Heat-Resistant Materials. ASM International, Metals Park, Ohio. ISBN 0871705966; 1997. $591 \mathrm{p}$

[27] Chandra T, Kuchlmayr R. Effect of strain rate on sigma formation in ferrite-austenite stainless steel at high temperatures. Journal of Materials Science. 1988;23:723-728

[28] Stejskalová Š, Kander L, et al. Study of Mechanical Properties and Microstructure Of Austenitic Stainless Bend Tubes, T-44/2014 Technical Report, Ostrava September; 2014 (in Czech)

[29] Kander L, Stejskalová Š, Čížek P. The change of the structure and mechanical properties of the austenitic steels after exposure at the critical temperature. In: Conference Proceedings METAL 2016: 25th Anniversary International Conference on Metallurgy and Materials; 25.-27.5; Brno, Czech Republic, Ostrava, Czech Republic, EU: TANGER Ltd., ISBN 978-80-87294-67-3; 2016. p. 724-729

[30] Small Punch Test Method for Metallic Materials. Cen Workshop Agreement CWA 15627, 2007

[31] Stejskalová Š, Kander L, Hermanová Š. The change of the structure and mechanical properties of the austenitic steels after exposure at the critical temperature. In: Longauerová $M$, Horňák P, Zubko P, editors. Metallography XVI: 16th International Symposium on Metallography and Materials Science; April 20-22; Stará Lesná, Slovakia. Switzerland: Trans Tech Publications; 2016. p. 330-334 
[32] Korčáková L, Kander L, Montgomery M, Jensen HT, Stejskalová Š. The influence of sigma phase precipitation on the mechanical properties of TP $347 \mathrm{H}$ austenitic steels after 100,000. In: Matocha K, Hurst R, Sun W, editors. The 3rd International Conference SSTT 2014: Determination of Mechanical Properties of Materials by Small Punch and Other Miniature Testing Techniques; 2014. Castle Seggau, Austria: OCELOT, ISBN 978-80-2606722-1; 2014. p. 119-132

[33] Kander L. Evaluation of Effect of Bending on Structure and Mechanical Properties of Austenitic Steels Super 304H, HR3C and TP347HFG using Small Punch Tests, T-63/2011, Materiálový a metalurgický výzkum. Ostrava, T-11/2011 (in Czech)

[34] Pomikálek L, Hermanová Š, Dobrovodská L. Effect of welding on the properties of HR3C, super 304H, Tp347HFG and P92 steels. In: Metal 2013: 22nd International Conference on Metallurgy and Materials; may 15-17; Brno, Czech Republic. Ostrava: Tanger; 2013. p. $806-811$

[35] Seifert W. Statistische Kenngrössen aus der Ausvertung von Zeitstandversuchen. In: Warmfeste metallische Werkstoffe; Zittau. Kammer der Technik. 1987. p. 129

[36] Kimmins ST, Coleman MC, Smith DJ. An overview of creep failure associated with heat affected zone of ferritic weldments. In: Creep and Fracture of Engineering. Materials and Structures. London: The Institute of Metals; 1993. p. 681-694

[37] Larson FR, Miller J. Time-temperature relationship for rupture and creep stresses. Transactions of the ASME. 1952;74:735-775

[38] VdTÜV-Werkstoffblatt 550 - Warmfester Walz- und Schmiedestahl X10CrNiCuNb18-9-3, Düsseldorf : VdTÜV, 12/2010

[39] VdTÜV-Werkstoffblatt 546 - Warmfester Walz- und Schmiedestahl X6CrNiNbN25-20 (1.4952), Düsseldorf : VdTÜV, 12/2009

[40] Tortorelli PF, Unocic KA, Wang H, Santella ML, Shingledecker JP. Alloys for advanced Ultrasupercritical (A-USC) steam boilers. In: EPRI. Crosscutting Research Materials Program DOE Fossil Energy; April 20; Pittsburgh, Pennsylvania. 2016

[41] Price AT, Williams JA. Influence of welding on creep properties of steels. In: Wilshire B, editor. Recent Advances in Creep and Fracture of Engineering Materials and Structures. Swansea: Pineridge Press; 1982. p. 265-353

[42] Etienne CF, Heerings JH. Evaluation of the influence of welding on creep resistance. Steel Research. 1995;65:187-196

[43] Sobotka J, Bobek J, Sobotková M. Long-term creep strength and SRF for welded joints of 316H steel boiler tubes. In: Stainless Steel 96. Düsseldorf: VDEh; 1996. p. 363-367

[44] Di Gianfrancesco A, editor. Materials for Ultra-Supercritical and Advanced UltraSupercritical Power Plants. Duxford: Woodhead Publishing; ISBN 9780081005583; 2016. $900 \mathrm{p}$ 